\title{
Geyser periodicity and the response of geysers to deformation
}

\author{
S. E. Ingebritsen \\ U.S. Geological Survey, Menlo Park, California
}

\author{
S. A. Rojstaczer \\ Department of Geology and Center for Hydrologic Science, Duke University, Durham, North Carolina
}

\begin{abstract}
Numerical simulations of multiphase fluid and heat transport through a porous medium define combinations of rock properties and boundary conditions which lead to geyser-like periodic discharge. Within the rather narrow range of conditions that allow geyser-like behavior, eruption frequency and discharge are highly sensitive to the intrinsic permeabilities of the geyser conduit and the surrounding rock matrix, to the relative permeability functions assumed, and to pressure gradients in the matrix. In theory, heat pipes (concomitant upward flow of steam and downward flow of liquid) can exist under similar conditions, but our simulations suggest that the periodic solution is more stable. Simulated time series of geyser discharge are chaotic, but integrated quantities such as eruption frequency and mass discharge per eruption are free of chaos. These results may explain the observed sensitivity of natural geysers to small strains such as those caused by remote earthquakes, if ground motion is sufficient to induce permeability changes.

Changes in geyser behavior caused by minor preseismic deformation, periodic surface

loading, and Earth tides are more difficult to explain in the context of our current model.
\end{abstract}

\section{Introduction}

Geysers are periodically discharging hot springs or fountains driven by steam or (less commonly) noncondensible gas. They are rare; perhaps $400-900$ exist worldwide, of which $\sim 200-500$ occur in the great geyser basins of Yellowstone National Park [Rinehart, 1980; Bryan, 1995]. For comparison, the number of steadily flowing hot springs worldwide is probably of the order of $10^{5}$. Geyser eruptions typically pass through several stages [White, 1967]: (1) initial overflow of liquid water at temperatures less than or equal to the local boiling point; (2) fountaining, liquid-dominated discharge; and (3) steam-dominated discharge of progressively decreasing intensity. Discharge then ceases for an interval.

Most geysers occur in areas where the water table is near the land surface, subsurface temperatures are at or near the boiling point to significant depths, and vertical pressure gradients are somewhat in excess of boiling point hydrostatic. Such conditions are most commonly found in the discharge areas of major hydrothermal systems. Maximum measured temperatures in drilled geyser areas generally exceed $170^{\circ} \mathrm{C}$ [White, 1967], and chemical geothermometry suggests that the water discharged from Old Faithful, Yellowstone, has boiled adiabatically from a temperature of about $215^{\circ} \mathrm{C}$ [Fournier, 1989] . At Yellowstone (surface boiling temperature $\sim 92^{\circ} \mathrm{C}$ ), this temperature corresponds to a boiling point hydrostatic depth of about $230 \mathrm{~m}$. However, research drilling in the thermal areas of Yellowstone has revealed vertical pressure gradients consistently in excess of $110 \%$ of hydrostatic and ranging as high as $147 \%$ of hydrostatic [White et al., 1975].

Copyright 1996 by the American Geophysical Union.

Paper number 96JB02285. 0148-0227/96/96JB-02285\$09.00
Our interest in geysers was provoked by various observations that indicate their sensitivity to small strains in the Earth. Fairly compelling data document geyser responses to coseismic strains of the order of 1 microstrain ( $\mu$ strain) [e.g., Silver and Vallette-Silver, 1992], barometric strains of about $0.1 \mu$ strain [White, 1967], and diurnal tidal strains of about $0.01 \mu$ strain [Rinehart, 1972]. More speculative correlations have been suggested between geyser activity and long-period tidal strains of about 1 nanostrain [Rinehart, 1972] (for a rebuttal, see White and Marler [1972]) and between geyser activity and preseismic strains [e.g., Silver and Vallette-Silver, 1992], which seem likely to be equally as small. The strain sensitivity is generally documented in terms of eruption frequency, one of the easiest geyser characteristics to measure.

Figure 1 shows two conceptual models of geyser systems: the classic model of a more-or-less open chamber constricted at the top (Figure 1a) and an alternative model that depicts a fracture zone surrounded by a less permeable rock matrix (Figure 1b). Our analysis can apply to either of these models; they share the essential characteristic of having a permeable conduit surrounded by less permeable and (presumably) less compliant rock. The upper part of the conduit of Yellowstone's Old Faithful has been examined via probe and video camera and shown to have cavernous porosity to a depth of at least $15 \mathrm{~m}$ [e.g., Kieffer et al., 1995]. However, it seems likely to us that the deeper parts of most geyser conduits consist of anastomozing fracture networks. Further, we doubt that the presence of a single constriction is crucial to geyser function because multiphase flows often show periodic behavior in systems that lack such constrictions, for example, in trickle beds [e.g., Dankworth et al., 1990] and open expansion chambers [e.g., Tae-il et al., 1993].

Most previous attempts to numerically simulate geyser behavior [e.g., Dowden et al., 1991] or hydrothermal eruptions 

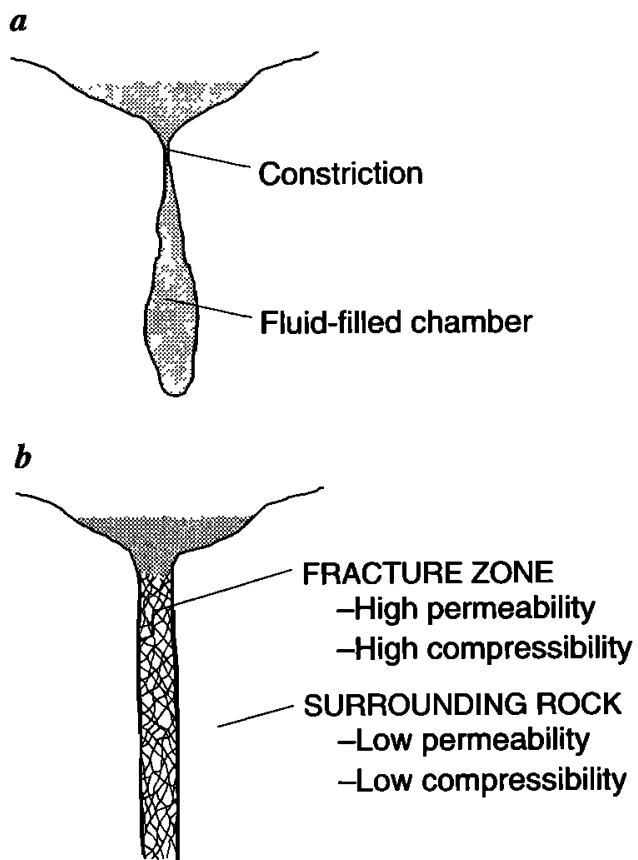

Figure 1. (a) Classical "chamber" or constricted-pipe model of geyser geometry and (b) "fracture zone" conceptual model. In both models, the geyser conduit is assumed to be more permeable and compressible than the surrounding rock matrix.

[e.g., Bercich and McKibbin, 1992] have been concerned with the eruption dynamics and have treated the eruptions as isolated, quasi steady state, and one-dimensional. Some work on geyser initiation and cycling has been performed in the laboratory using heated fluids in constricted or open chambers [e.g., Steinberg et al., 1982a; Tae-il et al., 1993]. Our own earlier work [Ingebritsen and Rojstaczer, 1993] involved transient numerical simulations of geyser initiation and cycling.

Most of our earlier simulations involved a 200 -m-deep, laterally isolated conduit, with a constant pressure-enthalpy upper boundary and a prescribed flux of steam or pure heat at the lower boundary. These boundary conditions are most appropriate for geysers that discharge through near-constantlevel pools and are fueled by steam rising from depth. They also apply to some of the laboratory models developed by Steinberg et al. [1982b, Figure 1]. With the pure-heat condition at the lower boundary, the upper boundary is the only source of mass, so if the heat flux is sufficient to generate a mobile steam phase (i.e., greater than about $2 \mathrm{~W} \mathrm{~m}^{-1}$ ), there are only two types of solutions that can conserve mass and energy. One is a "heat pipe" solution involving counterflow of liquid and steam, with constant flow rates such that the latent-heat difference between the phases is just sufficient to accommodate the basal heat flux. The other possibility is a periodic discharge, with the direction of the mass flux at the upper boundary reversing at (semi) regular intervals. None of the simulations described in our earlier work led to heat pipe behavior.

In this report, we present a more thorough analysis of the simulated geysering process. We first consider the geyser-like behavior of a laterally isolated conduit and examine the influence of various assumptions inherent in our mathematical model. We then increase the complexity of our simulations by relaxing the vertical and lateral boundary conditions to allow for lateral recharge and other variations in the mode of heat and mass recharge. Finally, we examine the conditions under which heat pipe behavior may occur and identify chaotic aspects of the simulated geysers. We then use the various simulation results to understand the conditions required for geysering and as a framework for examining the response of natural geysers to small strains.

\section{Mathematical Approach}

Our simulations employed the heat and mass flow program HYDROTHERM [Hayba and Ingebritsen, 1994]. This computer program is a descendent of multiphase geothermal-simulation models developed by the U.S. Geological Survey in the late 1970s [Faust and Mercer, 1979a, 1979b]. It solves finite difference approximations to expressions of mass and energy conservation that are posed in terms of pressure and enthalpy:

$$
\begin{aligned}
& \partial\left(n \rho_{\mathrm{f}}\right) / \partial t-\nabla \cdot\left[k k_{r s} \rho_{s} / \mu_{s} \cdot\left(\nabla P-\rho_{s} g \nabla D\right)\right] \\
& -\nabla \cdot\left[k k_{r w} \rho_{w} / \mu_{w} \cdot\left(\nabla P-\rho_{w} g \nabla D\right)\right]-q_{m}=0
\end{aligned}
$$

and

$$
\begin{array}{r}
\partial / \partial t\left[n \rho_{f} h_{f}+(1-n) \rho_{r} h_{r}\right] \\
-\nabla \cdot\left[k k_{r s} \rho_{s} h_{s} / \mu_{s} \cdot\left(\nabla P-\rho_{s} g \nabla D\right)\right] \\
-\nabla \cdot\left[k k_{r w} \rho_{w} h_{w} / \mu_{w} \cdot\left(\nabla P-\rho_{w g} g \nabla D\right)\right] \\
-\nabla \cdot K_{m} \nabla \mathrm{T}-q_{h}=0,
\end{array}
$$

respectively, where $n$ is porosity, $\rho$ is density, $t$ is time, $k$ is the intrinsic permeability tensor, $k_{r}$ is relative permeability, $\mu$ is viscosity, $P$ is pressure, $g$ is gravitational acceleration, $D$ is depth, $q$ is a source or sink, $h$ is fluid enthalpy, $K_{m}$ is medium thermal conductivity, and $T$ is temperature. The subscripts $s$, $w, m, r$, and $h$ denote steam, liquid water, mass, rock, and energy, respectively. The density $\left(\rho_{f}\right)$ and enthalpy $\left(h_{f}\right)$ of the fluid in place are defined by

$$
\rho_{f}=S_{w} \rho_{w}+S_{s} \rho_{s}
$$

and

$$
h_{f}=\left[h_{w} S_{w} \rho_{w}+h_{s} S_{s} \rho_{s}\right] /\left[S_{w} \rho_{w}+S_{s} \rho_{s}\right],
$$

where $S_{w}$ and $S_{s}$ are volumetric liquid and steam saturations, respectively, and $S_{w}+S_{s}=1$.

There are a number of assumptions inherent in these governing equations [Faust and Mercer, 1979a; Hayba and Ingebritsen, 1994]. With respect to the geyser problem, the most important are that a two-phase form of Darcy's law is valid, that rock and water are in local thermal equilibrium, that relative permeabilities to the two phases can be represented as nonhysteretic functions of liquid volume saturation, and that capillary effects are negligible (i.e., no difference in pressure between the fluid phases). It is difficult to estimate appropriate capillary-pressure functions for hydrothermal systems, as relevant data are limited. The surface tension of water decreases with temperature, so capillary-pressure effects 


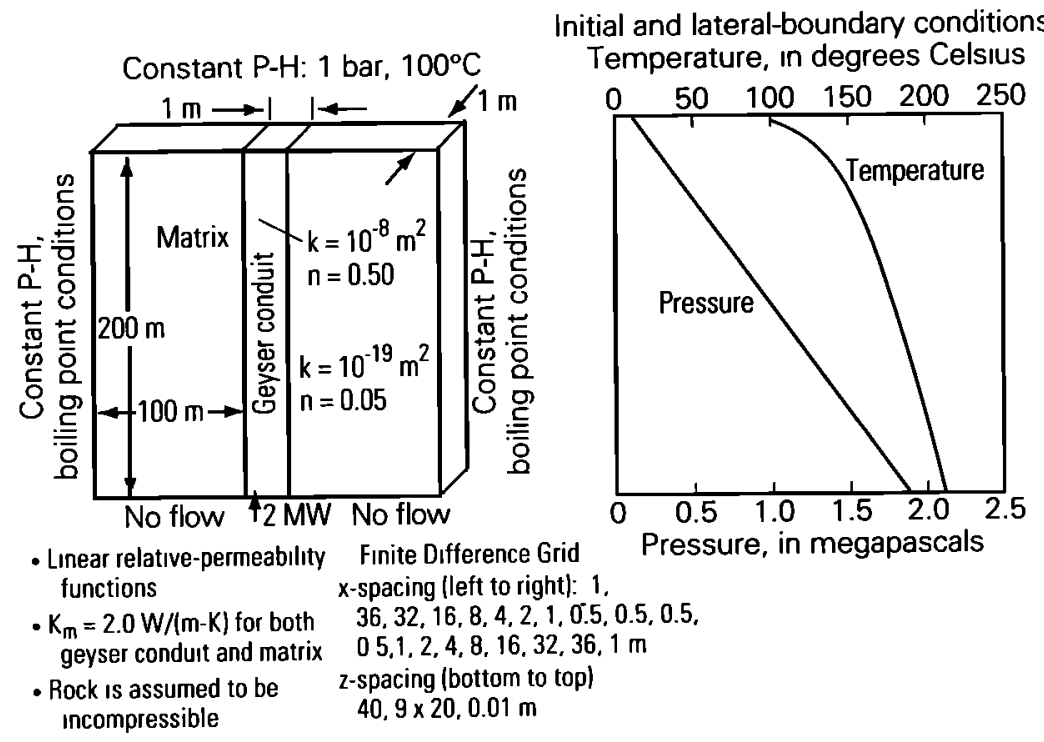

Figure 2. Two-dimensional model used in numerical simulations. The parameter values shown here, with linear relations for relative permeabilities, compose the "basic geyser model" referred to in the text. Note that there is free exchange of heat between geyser conduit and matrix but that the permeability of the matrix is so small that there is negligible exchange of mass. The linear relative permeability functions are $k_{r w}=\left(S_{w}\right.$ $-0.3) / 0.7$ and $k_{r s}=1-k_{r w}$, where $k_{r w}$ and $k_{r s}$ are relative permeabilities to liquid water and steam, respectively, and $S_{w}$ is volumetric liquid saturation.

should become relatively less important at high temperatures. The relative permeability functions can implicitly recognize some capillary effects by allowing for residual (immobile) water and steam saturations. The effects of assuming Darcian flow, local thermal equilibrium, and various relative permeability functions are discussed later, in the context of our numerical results.

The mass and energy balance equations are strongly coupled and highly nonlinear because a number of the independent variables are functions of the dependent variables. The relative permeabilities, densities, and viscosities, in particular, vary widely with pressure and enthalpy. The nonlinear coefficients are treated using Newton-Raphson iteration, giving rise to a system of linear equations. For one- or two-dimensional geometries, the system of equations is solved directly for each iteration [Faust and Mercer, 1979b]. Convergence is determined on the basis of mass and energy balances for each finite difference block [Hayba and Ingebritsen, 1994].

Values for the density, temperature, and viscosity of water, as well as the gradients and cross derivatives of each of these properties, are based on thermodynamic data for pure water [Haar et al., 1984; Sengers and Watson, 1986] and are obtained from a table of values embedded in the program. This method is fast and accurate, but the table is large, occupying 2 megabytes in compressed format. Under two-phase conditions, cubic splines are used to describe the positions of the saturated-liquid and saturated-steam curves, to calculate fluid properties, and to obtain the necessary derivatives [Hayba and Ingebritsen, 1994].

\section{Basic Geyser Model}

For purposes of continuity, we briefly summarize the pertinent aspects of our earlier results [Ingebritsen and Rojstaczer, 1993]. Most of our simulations involved a $1 \mathrm{~m}^{2}, 200-\mathrm{m}$ deep, high-permeability conduit embedded in a less permeable two-dimensional matrix (Figure 2). The upper boundary was maintained at a pressure of $0.1 \mathrm{MPa}$ and an enthalpy corresponding to liquid water at a temperature of $100^{\circ} \mathrm{C}$. The lateral boundaries were maintained at hydrostatic pressures and boiling point liquid enthalpies. The conduit was hydraulically isolated from the surrounding matrix and was supplied with a constant flux of heat from below (see the parameter values in Figure 2). The simuations thus approximate geyser eruptions through a shallow pool of water that provides an adequate source of mass recharge. Heat is obtained both from below and from surface recharge.

For particular combinations of conduit permeability and basal heat input, the behavior of this system is quite geyserlike. In Figure 3, results are posed in terms of total mass and steam flow rates (Figure 3a), volumetric liquid saturation (Figure $3 \mathrm{~b}$ ), and Darcy velocities of liquid and steam (Figure $3 c$ ). All of these quantities are evaluated at $10 \mathrm{~m}$ depth in the fracture zone, the depth to the center of the uppermost active finite difference block (Figure 2). The discharge is periodic, with a fairly steady period of 17-18 min that develops after a few cycles (Figure 3a). At the beginning of each eruption, there is a period of liquid-only discharge; at mideruption, there is two-phase flow that is only about $3 \%$ steam by mass but about $98 \%$ steam by volume because of the 800 -fold density difference between the two phases at $-0.2 \mathrm{MPa}(10-\mathrm{m}$ hydrostatic depth); and, finally, there is a period of steamonly flow that persists as long as there is a steam phase at 10 $m$ depth (Figure $3 b$ ). Thus the eruption stages mimic those observed at natural geysers.

Figure 4 shows saturation profiles in the conduit at various stages of the eruption cycles shown in Figure 3. When the eruption begins, steam is present only in the lower parts of the conduit. The volume expansion associated with further conversion of liquid to steam forces liquid up out of the conduit, depressurizing the conduit and causing more boiling. By mideruption, the conduit is filled with a two-phase mixture. 

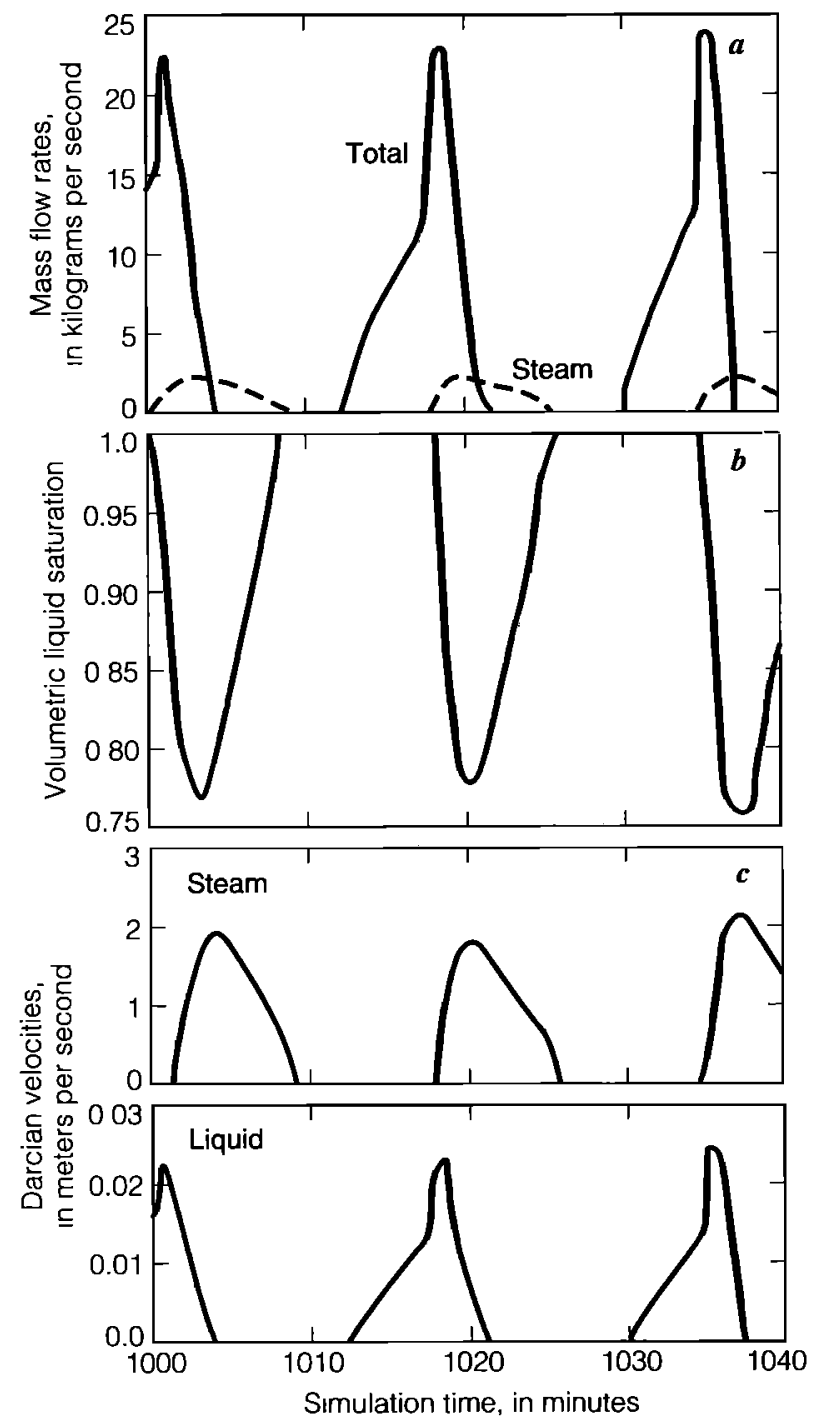

Figure 3. (a) Mass flow rates, (b) volumetric liquid saturation, and (c) Darcy velocities at $10 \mathrm{~m}$ depth for geyser cycles obtained using the parameters shown in Figure 2.

Although the eruption seems to be triggered by a steam phase at $>100 \mathrm{~m}$ depth, most of the mass discharge is derived from relatively shallow depths. The contribution from any depth interval can be determined by integrating between the preeruption and posteruption saturation curves of Figure 4; in this particular example, about $60 \%$ of the mass erupted came from $<40 \mathrm{~m}$ depth.

\section{Sensitivity Analyses}

A series of sensitivity analyses further demonstrates the behavior of our basic geyser model (Figure 2). Increasing the porosity of the geyser conduit increases the time required to resaturate the conduit and also increases its bulk heat capacity, leading to less frequent, larger eruptions (Figure 5a). Varying basal heat input in the range of 0.5-5 MW affects eruption magnitude but not eruption frequency (Figure 5b). Considering the discharge part of the geyser cycle only, this range of heat input values leads to time-averaged heat and mass discharge rates of $1-9 \mathrm{MW}$ and $1.5-12 \mathrm{~kg} \mathrm{~s}^{-1}$, respec- tively, rates which encompass those of most natural hot springs and geysers. Old Faithful, Yellowstone, for example, discharges at a time-averaged rate of about $6 \mathrm{~kg} \mathrm{~s}^{-1}$ [Kieffer, 1989], which equates to approximately $5 \mathrm{MW}$ if the geyser is recharged from a $215^{\circ} \mathrm{C}$ reservoir as suggested by Fournier [1989] or approximately $2.5 \mathrm{MW}$ if one considers only the highest temperature measured for discharged water (118-127 $\left.{ }^{\circ} \mathrm{C}\right)$ (S.W. Kieffer, written communication, 1996). In simulations of our basic model (Figure 2), heat discharge rates exceed the basal heat input rates by about a factor of 2 , because significant heat is supplied by recharge from the upper boundary. Varying upper boundary temperatures (Figure 5c) and pressures (Figure 5d) over reasonable ranges has only a minor effect on the geyser cycle. Decreasing conduit area (Figure 5e) inhibits mass recharge. Because basal heat input is held constant, solutions for conduit areas $<0.2 \mathrm{~m}^{2}$ show long periods of steady steam discharge interspersed with brief liquid recharge/discharge events. Decreasing conduit length (Figure 5f) leads to smaller, more frequent eruptions.

\section{Limits to Geyser-like Behavior}

The periodic discharge from our basic model (Figure 2) has geyser-like characteristics only for a narrow range of conduit permeabilities centered on a value of about $10^{-8} \mathrm{~m}^{2}$. Assigning a permeability of $10^{-9} \mathrm{~m}^{2}$ led to long periods of steady steam discharge interpersed with brief liquid recharge/discharge events (Figure 6). For just slightly lower permeabilities (e.g., $0.8 \times 10^{-9} \mathrm{~m}^{2}$ ), the conduit could not transmit the $2 \mathrm{MW}$ heat input used in our basic geyser model. Because there is an approximately $\log$ linear relation between conduit permeability and eruption frequency (Figure 7), increasing permeability led rapidly toward a high-frequency cycling that could be perceived as steady boiling or bubbling. Simulations using different conduit geometries or rates of basal heat input would presumably lead to geyser-like behavior over different but similarly narrow permeability ranges.

The results shown in Figures 5 and 7 suggest that geysereruption frequency is quite sensitive to the hydraulic properties and dimensions of the geyser conduit and less sensitive to the boundary conditions imposed on the conduit. This inference is consistent with results described in a later section, which demonstrate that geyser-eruption frequency is largely independent of the source of mass recharge.

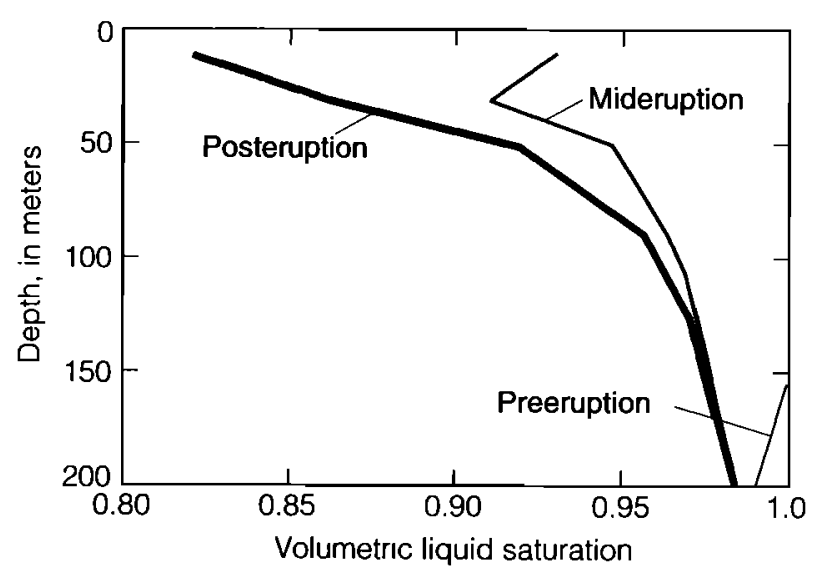

Figure 4. Volumetric liquid saturation within the geyser conduit at selected times during the geyser cycles shown in Figure 3. 

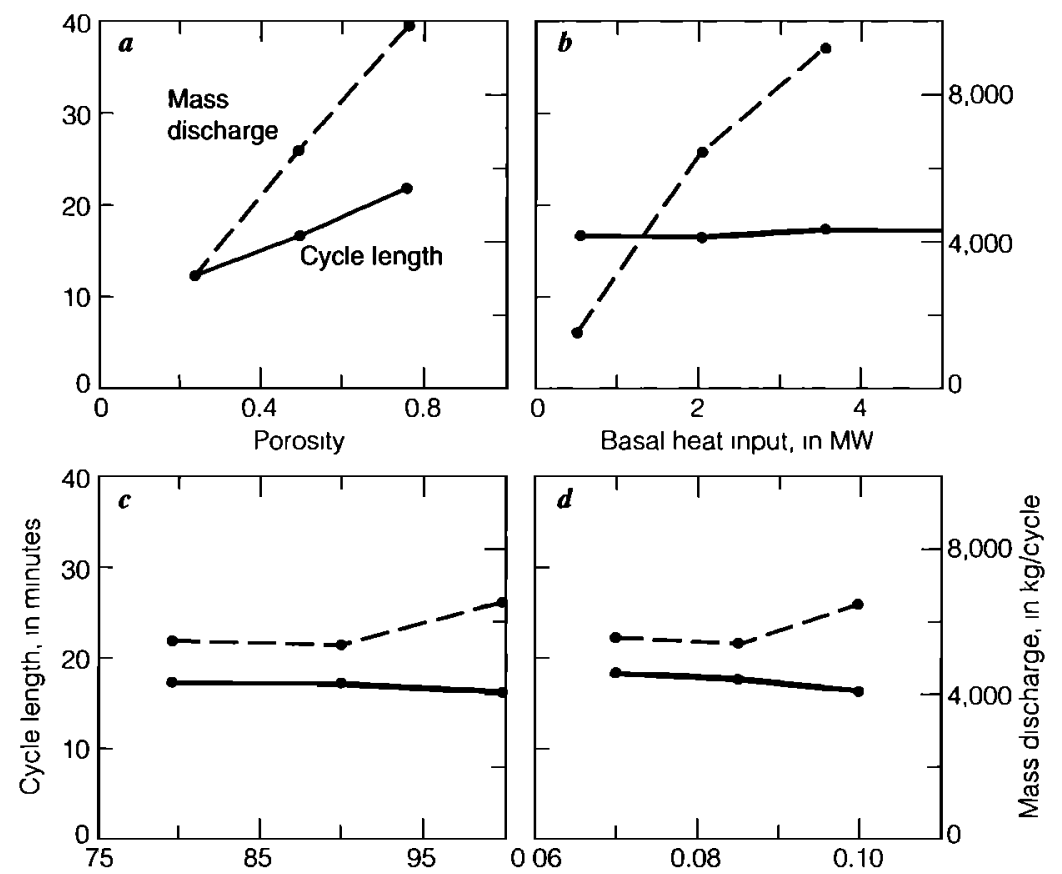

Temperature at upper boundary, in ${ }^{\circ} \mathrm{C}$ Pressure at upper boundary, in $\mathrm{MPa}$

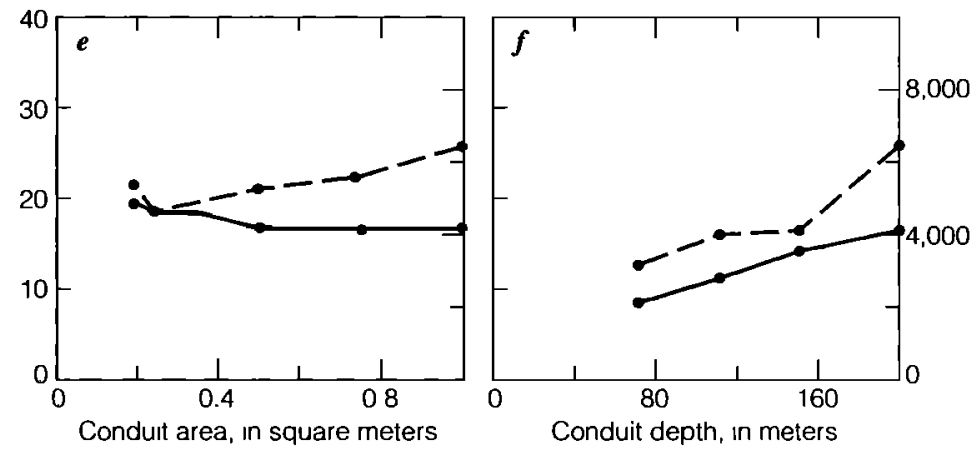

Figure 5. Geyser eruption frequency and mass discharge/cycle as functions of (a) porosity of the geyser conduit, (b) rates of basal heat input, (c) temperature and (d) pressure at the top of the geyser conduit, (e) conduit area, and (f) conduit depth. Other parameters are as shown in Figure 2.

\section{Influence of Assumptions}

The basic geyser model described above, while a useful tool to examine controls on geyser periodicity, contains many simplifications and implicit assumptions. We assumed that Darcy's law controlled flow of steam and liquid throughout the conduit and eruption cycle, that there was instantaneous thermal equilibrium between water and rock, and that the relative permeability functions for steam and water were linear functions of saturation. It is worthwhile to examine the influence of these assumptions on our results.

Darcy's Law. By invoking Darcy's law we assume linearlaminar flow. Near-vent flow rates during geyser eruptions [Kieffer, 1989] are high enough that flow is clearly in the turbulent regime, but perhaps Darcy's law reasonably describes flow at greater depths and (or) flow during less active parts of the geyser cycle. The threshold for nonlinear flow is usually estimated as a function of the Reynold's number, $R e=$ $(\rho v d) / \mu$, where $v$ is velocity and $d$ is a characteristic length. In order to calculate maximum $R e$ values for our simulations, we can take $\rho, v$, and $\mu$ at $10 \mathrm{~m}$ depth $(0.2 \mathrm{MPa})$. We also need some way to estimate $d$. For a porous medium, $d$ may be approximated as $k^{1 / 2}$ [Ward, 1964], the transition to nonlinear flow takes place at $R e \sim 5$ [Bear, 1979; Freeze and Cherry, 1979], and the volumetric flow rate or Darcy velocity $\left(v_{\mathrm{D}}\right)$ is used in calculating $R e$. On this basis, and neglecting any interference or other interaction between phases, we can estimate that for a $k$ value of $10^{-8} \mathrm{~m}^{2}$ (Figure 2), the flow becomes nonlinear when steam reaches a Darcy velocity of $\sim 0.4 \mathrm{~m} \mathrm{~s}^{-1}$ or liquid reaches a Darcy velocity of $\sim 0.01 \mathrm{~m} \mathrm{~s}^{-1}$. In comparison, our maximum simulated Darcy velocities at $10 \mathrm{~m}$ depth are about $2 \mathrm{~m} \mathrm{~s}^{-1}$ and $0.02 \mathrm{~m} \mathrm{~s}^{-1}$ for steam and liquid, respectively (Figure 3c). Alternatively, the linear/nonlinear transition velocities can be estimated via a parallelplate fracture permeability model: $d$ can be taken as the aperture, and the critical $R e$ value can be taken as about 1,000 [Vennard and Street, 1975]. Assuming $k=N d^{3} / 12$ [Snow, 1968], a $k$ of $10^{-8} \mathrm{~m}^{2}$ implies $d$ in the range of $0.001-0.005 \mathrm{~m}$ for $N$ (fracture density) in the range of $1-100 \mathrm{~m}^{-1}$. In this case the actual fluid-particle velocities in the fractures are the appropriate values to use in calculating $R e$. We will consider the steam phase only because of its far greater volume: for $N$ in the range of $1-100$, the maximum simulated Darcy velocity 

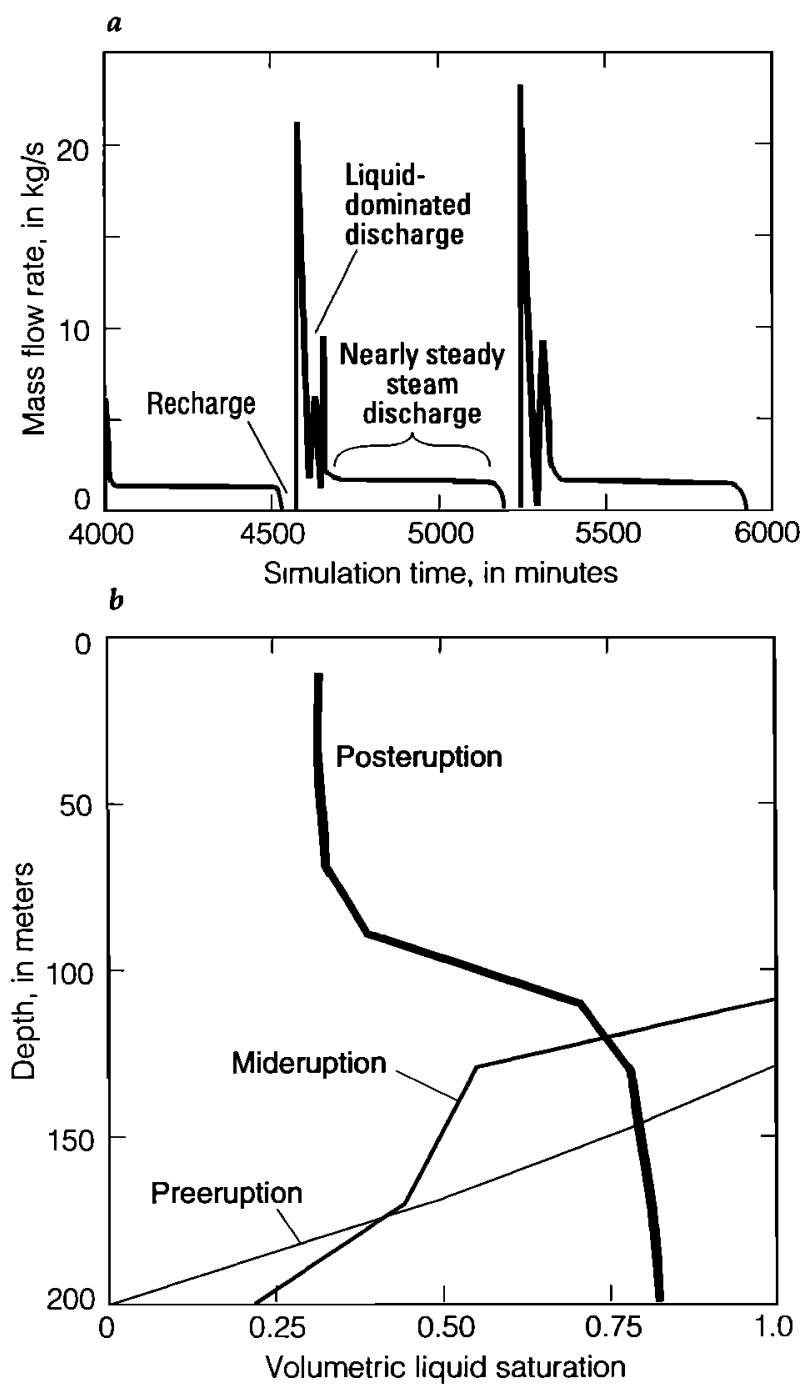

Figure 6. (a) Mass flow rate (liquid water plus steam) at 10 $m$ depth for a conduit permeability of $10^{-9} \mathrm{~m}^{2}$ and other parameters as shown in Figure 2 and (b) volumetric liquid saturation within the geyser conduit at selected times during the geyser cycles shown in Figure 6a. The preeruption, mideruption, and posteruption saturations are substantially lower than those obtained with 10 times greater permeability (Figure 4).

of $2 \mathrm{~m} \mathrm{~s}^{-1}$ (Figure 3c) translates to particle velocities of 20-400 $\mathrm{m} \mathrm{s}^{-1}$, whereas the flow is predicted to become nonlinear at $1.5-8 \mathrm{~m} \mathrm{~s}^{-1}$. The simulated velocities are thus somewhat larger than the linear/nonlinear transition velocities predicted by both the porous medium and parallel-plate approaches. In the uppermost part of the conduit, flow is predicted to be in the nonlinear laminar or turbulent range, so that the assumption of Darcian flow may be inappropriate during parts of some of our simulations. Adding a velocity-dependent turbulent-drag term to the governing equations would likely reduce the maximum simulated velocities.

The relation between the simulated Darcy velocities shown in Figure $3 \mathrm{C}$ and the inferred fluid-particle velocities depends on the effective porosity and volumetric saturations. The data and analyses of Kieffer [1984, 1989] strongly suggest near-vent fluid-particle velocities of tens of meters per second at mideruption. Volumetric steam flow rates increase towards the vent, due to the combined effects of increasing vaporization and a volume expansion which roughly obeys the ideal gas law. Volumetric liquid flow rates may actually decrease slightly toward the vent due to vaporization and contraction of the remaining, cooling liquid.

Heat exchange with the rock. In our earlier work, we assumed that thermal equilibrium between water and rock was instantaneous; there was no actual calculation of waterrock heat exchange. This assumption is commonly made in geothermal reservoir engineering and is reasonable if fluid flow is relatively slow or steady; however, it may be inappropriate for rapid transients. In order to evaluate the influence of heat exchange with the rock on our basic geyser model (Figure 2), we did sets of simulations assuming (1) perfect heat exchange and (2) no heat exchange. Both showed eruption frequency and mass discharge to be roughly log linear functions of conduit permeability (Figure 7). The curves representing "perfect exchange" and "no exchange" are offset; presumably, models that explicitly calculate water-rock heat exchange would predict results that fall between these limiting curves, with the exact position depending on assumptions about fracture spacing and (or) pore structure. For a given permeability, the eruptions with no water-rock heat exchange are somewhat smaller and more frequent, but the effect is minor (Figure 7). The assumption of perfect heat exchange with the rock apparently has little effect on the simulated geyser cycles.

Relative permeability functions. In our basic geyser model, we assumed that relative permeability was a linear function of saturation. This functional relationship is a significant source of nonlinearity in the governing equations. We can increase the degree of nonlinearity by assuming that the relative permeability is described by Corey-type [Corey, 1957] or "fracture flow" [Sorey et al., 1980] functions (Figure 8). The nonlinear relative permeability functions greatly affect the relationship between the intrinsic permeability of the geyser conduit, geyser frequency, and mass discharge per eruption (Figure 9). Further, the nature of system behavior at a particular value of intrinsic permeability is greatly changed, as

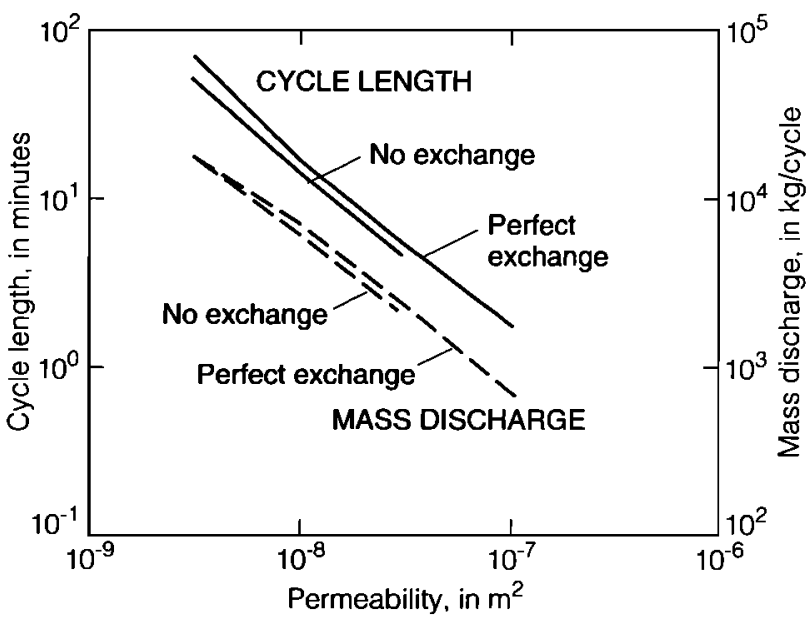

Figure 7. Geyser eruption frequency and mass discharge/cycle as functions of permeability for sets of simulations assuming perfect water-rock heat exchange (curves labeled "perfect exchange") and no water-rock heat exchange ("no exchange"). Parameter values are as shown in Figure 2. 


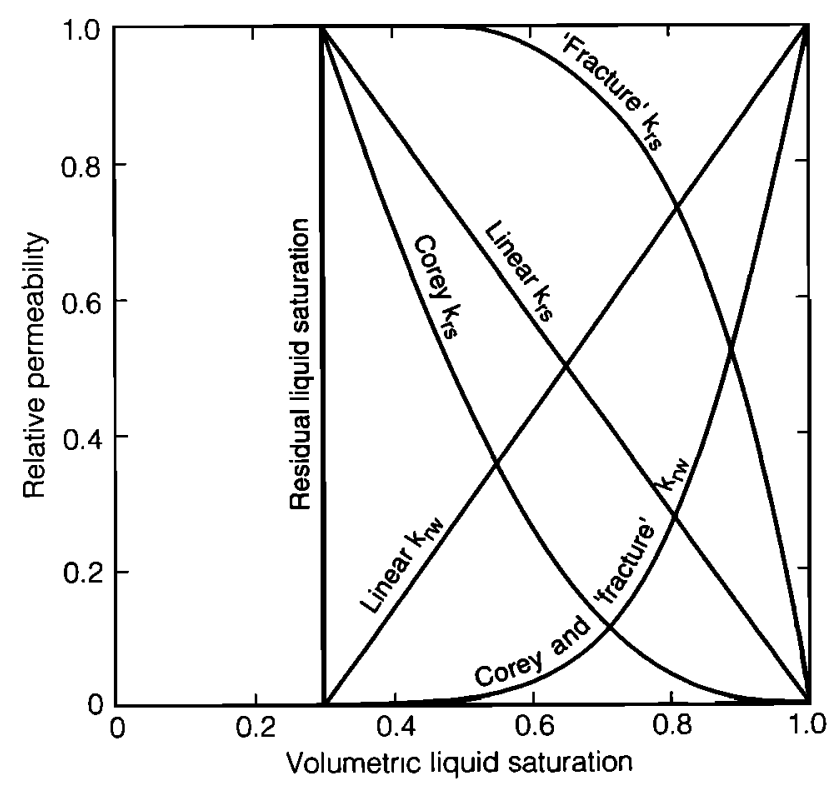

Figure 8. Relative permeability functions used in numerical simulations.

illustrated by power spectra of the surface discharge for the "linear geyser" and "Corey geyser" at a permeability of $10^{-8}$ $\mathrm{m}^{2}$ (Figure 10). Whereas the linear geyser shows discharge dominated by a 17-18 min period, the Corey geyser exhibits a much more complex response. Periodicity in discharge is multimodal, with the two largest periods at 60 and $40 \mathrm{~min}$. Mass discharge is highly correlated with geyser frequency (Figures 7 and 9) and, as a result, the Corey geyser has eruptions 2-4 times larger than the linear geyser, depending on the period.

We know of no data that would allow empirical estimation of relative permeability functions for natural geysers. Since relative permeabilities, like intrinsic permeabilities, depend largely on the geometry of void spaces, it seems likely that different relations might apply in different parts of any

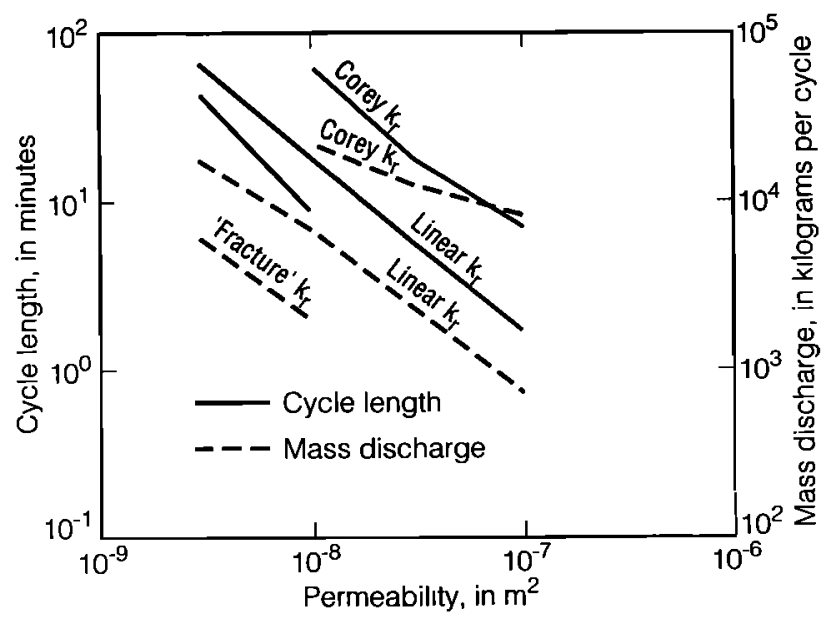

Figure 9. Geyser eruption frequency and mass discharge/cycle as functions of permeability for sets of simulations with various relative permeability functions. The relative permeability functions are shown in Figure 8, and other parameter values are as shown in Figure 2.

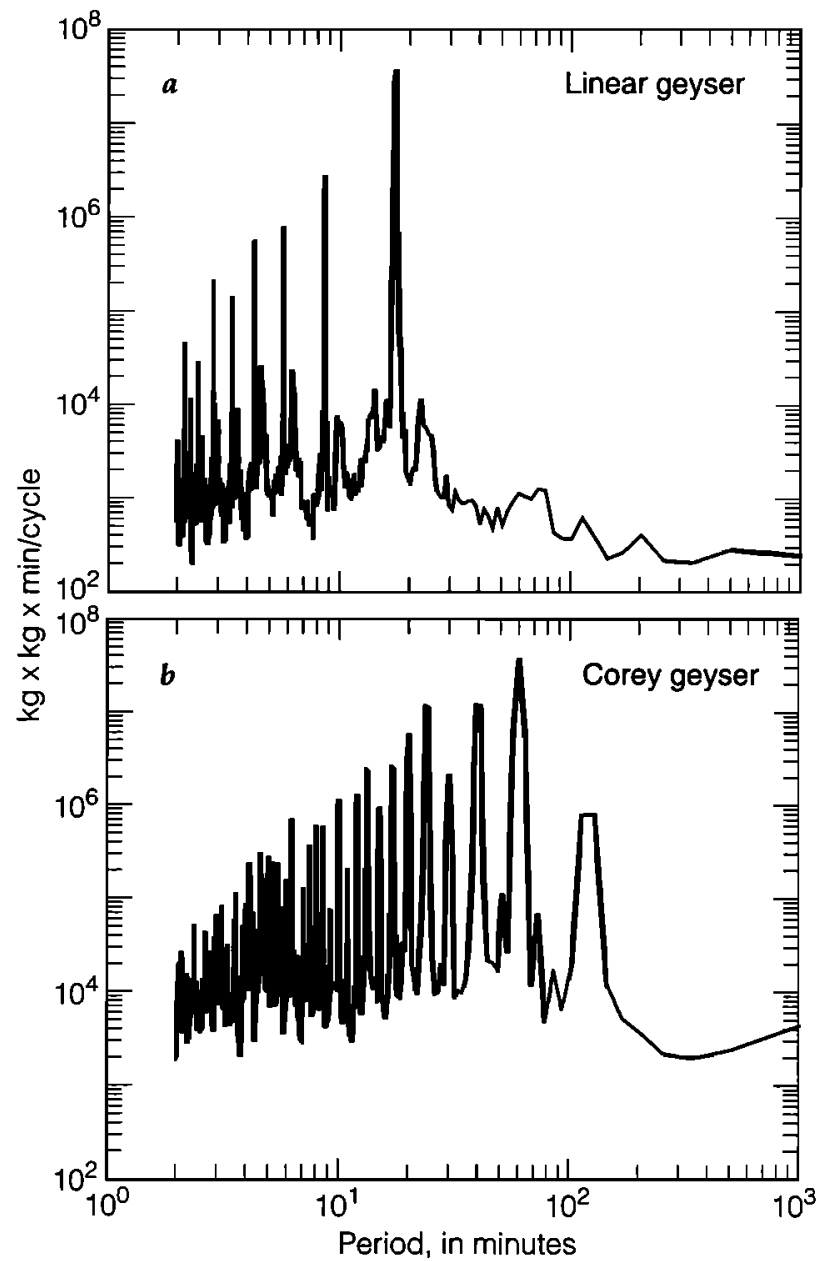

Figure 10. Power spectra of mass flux for the (a) "linear geyser" and (b) "Corey geyser." Each spectrum shows the principal periods in the geyser cycle in minutes. With the exception of Corey-type relative permeabilities for the Corey geyser, parameter values are as shown in Figure 2.

particular geyser system. Spatial variability in both intrinsic and relative permeabilities may contribute substantially to the complex behavior [Nicholl et al, 1994] of many natural geysers. The dependence of geyser behavior on the assumed relative permeability function suggests that our geyser model possesses some degree of chaos, an issue that is examined in a later section.

\section{Sources of Mass Recharge}

As indicated above, the boundary conditions imposed in our basic model (Figure 2) are most appropriate for geyser conduits that capture steam upflow and discharge through a constant-level pool that can also supply mass recharge. Field relations [e.g., White et al., 1975] and geochemical interpretations [e.g., Fournier, 1969, 1989] suggest that most natural geysers are actually recharged by fluids rising from depth and (or) converging laterally toward the geyser conduit. In this section, we explore the effects of (1) mass recharge from below and (2) increased hydraulic communication between the geyser conduit and the surrounding rock matrix. In systems which receive mass recharge from sources other than the 
upper boundary, steady cocurrent two-phase upflow is a possibility, and the limits to periodic behavior are of particular interest. The results described in this section indicate that for conditions under which periodic behavior persists, the geysereruption frequency is largely independent of the source of mass recharge (above, below, or the sides). This is consistent with the previously described sensitivity analyses that showed frequency to be strongly affected by the hydraulic properties of the geyser conduit and less affected by conditions at the boundaries of the conduit. In contrast, eruption magnitude seems to be quite sensitive to conditions at the conduit boundaries. Since frequency is the main parameter of interest, we return in later sections to the simple basic geyser model (Figure 2) to discuss heat pipe solutions and nonlinear behavior.

\section{Mass Recharge from Below}

To consider mass recharge from below, we modified the lower boundary condition, specifying steady fluxes of fluid at enthalpies ranging from $1000 \mathrm{~kJ} \mathrm{~kg}^{-1}$ (the enthalpy of liquid water at $200 \mathrm{~m}$ depth on the hydrostatic boiling point curve) to $2800 \mathrm{~kJ} \mathrm{~kg}^{-1}$ (the maximum enthalpy of saturated steam). For a conduit permeability of $10^{-8} \mathrm{~m}^{2}$, a fairly wide range of mass upflow rates led to periodic discharge; a number of examples are summarized in Table 1 . Injection of $0.72 \mathrm{~kg} \mathrm{~s}^{-1}$ of steam $\left(2800 \mathrm{~kJ} \mathrm{~kg}^{-1}\right)$ caused geyser cycles very similar to those caused by an equivalent ( $2 \mathrm{MW}$ ) input of pure heat.

In these simulations, we examined the response for three relative permeability functions: linear, Corey, and fracture flow (Figure 8). For a given relative permeability function, varying mass input in the range of $0-10 \mathrm{~kg} \mathrm{~s}^{-1}$ caused eruption frequency to vary only by $25 \%$ or less, whereas mass discharge per eruption varied by as much as a factor of 5 . With an increased conduit permeability of $10^{-7} \mathrm{~m}^{2}$, most of the mass flux boundary conditions listed in Table 1 led to steady cocurrent two-phase upflow, perhaps indicating that some degree of resistance to steam expansion is a key to the periodic discharge.

\section{Lateral Recharge}

In our basic geyser model (Figure 2), there is free exchange of heat between geyser conduit and surrounding matrix, but the permeability of the matrix is so low that there is little hydraulic communication. Because the lateral boundaries are maintained at hydrostatic pressures and pressure in the geyser conduit fluctuates about a hydrostatic gradient, the hydraulic drive for lateral recharge is also small. If the conduit/matrix permeability contrast is $\geq 10^{4}$, the conduit functions as if it were hydraulically isolated [Ingebritsen and Rojstaczer, 1993]. Decreasing the permeability contrast from $10^{4}$ to $10^{3}$ causes a modest increase in eruption frequency, a substantial decrease in eruption magnitude, and a substantial increase in discharge enthalpy (Table 2). A permeability contrast of $\leq 500$ extinguishes periodicity. It leads to steady steam upflow in the geyser conduit, as the small amount of lateral recharge $(\sim 0.6$ $\mathrm{kg} \mathrm{s}^{-1}$ ) is completely vaporized by the basal heat input.

The results are quite different if the lateral boundaries are maintained at superhydrostatic pressures similar to those suggested by the Yellowstone drilling data [White et al., 1975]. In this situation, there is a large drive for lateral recharge because pressures in the geyser conduit remain near-hydrostatic. Conduit/matrix permeability contrasts of $>3000$ lead to periodic discharge, whereas contrasts of $\leq 3000$ lead to steady, liquid-dominated upflow (Table 2). If the conduit/matrix permeability contrast is $\leq 10^{4}$, most mass recharge comes from the lateral boundaries, rather than the upper boundary.

In some simulations, we eliminated downflow at the top of the geyser conduit, forcing all mass recharge to pass through the less permeable rock matrix. This set of boundary condi-

Table 1. Results of Simulations Involving Mass Recharge From Below

\begin{tabular}{|c|c|c|c|c|c|c|}
\hline & $\begin{array}{c}\text { Mass Recharge } \\
\text { at Lower } \\
\text { Boundary, } \\
\mathrm{kg} \mathrm{s}^{-1}\end{array}$ & $\begin{array}{l}\text { Recharge } \\
\text { Enthalpy, } \\
\text { kJ kg }^{-1}\end{array}$ & $\begin{array}{c}\text { Equivalent } \\
\text { Basal Heat } \\
\text { Flux, } \\
\text { MW }\end{array}$ & $\begin{array}{l}\text { Cycle Length, } \\
\text { min }\end{array}$ & $\begin{array}{c}\text { Mass } \\
\text { Discharge per } \\
\text { Cycle, } \\
\text { kg }\end{array}$ & $\begin{array}{c}\text { Mass Recharge } \\
\text { From Upper } \\
\text { Boundary, } \\
\% \text { of Total }\end{array}$ \\
\hline \multirow[t]{5}{*}{ Linear $k_{r}$} & 0 & -- & 2 & 17 & 6,600 & 100 \\
\hline & 0.72 & 2,800 & 2 & 18 & 4,900 & 84 \\
\hline & 1.34 & 1,500 & 2 & 17 & 4,100 & 67 \\
\hline & 2.00 & 1,000 & 2 & 18 & 3,500 & 38 \\
\hline & 10.0 & 1,000 & 10 & 18 & 17,000 & 36 \\
\hline \multirow[t]{4}{*}{ Corey $k_{r}$} & 0 & - & 2 & 63 & 22,000 & 100 \\
\hline & 0.72 & 2,800 & 2 & 52 & 18,000 & 88 \\
\hline & 1.34 & 1,500 & 2 & 57 & 18,000 & 74 \\
\hline & 2.00 & 1,000 & 2 & 72 & 19,000 & 54 \\
\hline \multirow[t]{5}{*}{ "Fracture" $k_{r}$} & 0 & - & 2 & 8.7 & 1,900 & 100 \\
\hline & 0.72 & 2,800 & 2 & 9.3 & 1,500 & 73 \\
\hline & 1.34 & 1,500 & 2 & 8.9 & 1,400 & 49 \\
\hline & 2.00 & 1,000 & 2 & 9.4 & 5,400 & 79 \\
\hline & 10.0 & 1,000 & 10 & 9.6 & 6,600 & 13 \\
\hline
\end{tabular}

Except as indicated, all parameters and boundary conditions are as shown in Figure 2. 
Table 2. Results of Simulations Involving Lateral Mass Recharge

\begin{tabular}{cccccc}
\hline $\begin{array}{c}\text { Vertical } \\
\text { Pressure } \\
\begin{array}{c}\text { Gradient at } \\
\text { Lateral } \\
\text { Boundaries, } \\
\text { \% of Hydrostatic }\end{array}\end{array}$ & $\begin{array}{c}\text { Matrix } \\
\text { Permeability, } \\
\mathrm{m}^{2}\end{array}$ & $\begin{array}{c}\text { Conduit-Matrix } \\
\text { Permeability } \\
\text { Contrast }\end{array}$ & $\begin{array}{c}\text { Cycle Length, } \\
\text { min }\end{array}$ & $\begin{array}{c}\text { Mass Discharge } \\
\text { per Cycle, } \\
\text { kg }\end{array}$ & $\begin{array}{c}\text { Mass Recharge } \\
\text { From Upper } \\
\text { Boundary, } \\
\% \text { of Total }\end{array}$ \\
\hline 100 & $10^{-19}$ & $10^{11}$ & 17 & 6,600 & 100 \\
100 & $10^{-12}$ & $10^{4}$ & 17 & 4,800 & 96 \\
100 & $3 \times 10^{-12}$ & $3 \times 10^{3}$ & 16 & 4,600 & 97 \\
100 & $10^{-11}$ & $10^{3}$ & 15 & 1,400 & 78 \\
100 & $2 \times 10^{-11}$ & 500 & - & $0.62 \mathrm{~kg} \mathrm{~s}$ & 0 \\
125 & $10^{-12}$ & $10^{4}$ & 17 & 12,000 & 47 \\
125 & $2 \times 10^{-12}$ & $5 \times 10^{3}$ & 17 & 17,000 & 24 \\
125 & $3 \times 10^{-12}$ & $3 \times 10^{3}$ & - & $16 \mathrm{~kg} \mathrm{~s}$ & 0 \\
\hline
\end{tabular}

Except as indicated, all parameters are as shown in Figure 2.

tions often led to a continuous but unsteady discharge (Figure 11), with eruption frequency and magnitude both affected by matrix permeability.

\section{Are Heat Pipe Conditions Obtainable?}

In some geothermal regions of the world (e.g., The Geysers, California and Larderello, Italy), upward flow of steam is countered by concomitant downward flow of liquid. Vapor and liquid flow in opposite directions due mainly to gravity effects. Such a flow system, whether natural or engineered, is often termed a heat pipe [White et al, 1971]. (In the engineered version, the counterflow is generally driven by capillarity, rather than gravity.)

Natural heat pipes occur in hydrothermal environments that are very different from those in which geysering occurs; the heat pipes are often underpressured with respect to local hydrostatic pressure and are associated with low-discharge acid-sulfate springs, rather than the high-discharge neutral-

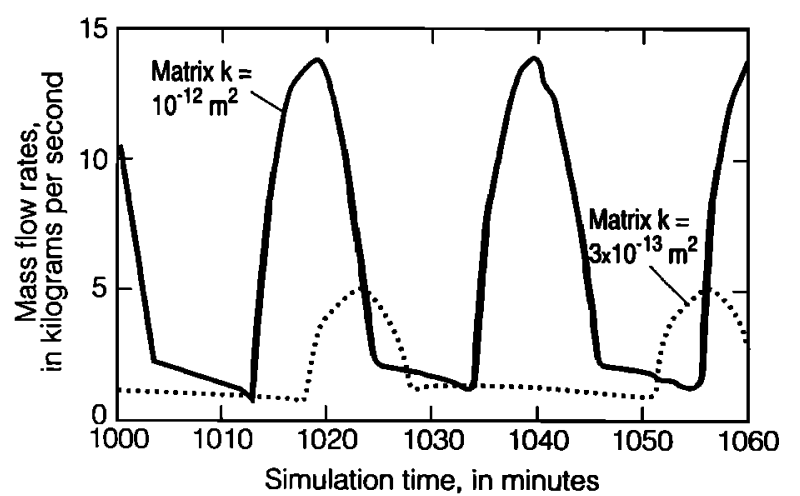

Figure 11. Mass flow rates at $10 \mathrm{~m}$ depth obtained by assigning matrix permeabilities of $3 \times 10^{-13} \mathrm{~m}^{2}$ and $1 \times 10^{-12} \mathrm{~m}^{2}$ and restricting downflow from the upper boundary. Pressure gradient at lateral boundaries is $125 \%$ of hydrostatic; other parameters are as shown in Figure 2. chloride springs typical of geyser areas. Nevertheless, there seem to be some mathematical similarities. In fact, heat pipe solutions have been found in numerical simulations of steamwater flow that employed boundary conditions and geometries similar to those that we use to simulate geysering [e.g., McGuinness et al., 1993]. The two solutions, geysers or heat pipes, may represent two states of a solution domain, with the specific solution depending upon the bifurcation parameters of the system [Ott, 1993], such as the degree of heating and the permeability of the conduit.

In our simulations, heat pipes do not occur unless we employ coarse time steps. For example, using our basic geyser model (Figure 2) and assuming a geyser-conduit permeability of $3 \times 10^{-8} \mathrm{~m}^{2}$, a balanced heat pipe (countercurrent flow of steam and liquid with no net mass discharge) develops after $2000 \mathrm{~s}$ when we use a maximum time step of $240 \mathrm{~s}$. However, if we use a time step of $120 \mathrm{~s}$ or less a periodic solution develops. The instability of the heat pipe solution can be demonstrated by using a heat pipe solution obtained with coarse time steps as the initial conditions for simulations employing a finer time step. In Figure 12, we show the effects of reducing the maximum time step to $20 \mathrm{~s}$ after a stable heat pipe solution had been obtained with a time step of $240 \mathrm{~s}$. With the shortened time steps, the solution evolves to a regular periodicity. It should be noted that the solutions at both time steps satisfy the conservation of mass and energy constraints embedded in our simulations.

In this context, it is worth noting the growing body of evidence that many steam-liquid systems exhibit periodic or aperiodic instabilities [e.g., McGuiness et al., 1993; $X u$ and Lowell, 1995, Young, 1996]. The dependence of our own heat pipe solutions on coarse time steps suggests that they are obtained only when perturbations are damped. In HYDROTHERM, the solution technique is fully implicit, and implicit solution techniques cause artificial smoothing of the solution as the time step is increased [e.g., Sod, 1985]. Our heat pipe solution appears likely to be a metastable one that depends on smoothing of temporal variations. However, quasi-steady heat pipes can exist in nature and may exist with boundary conditions similar to those we simulate. The bulk permeabil- 


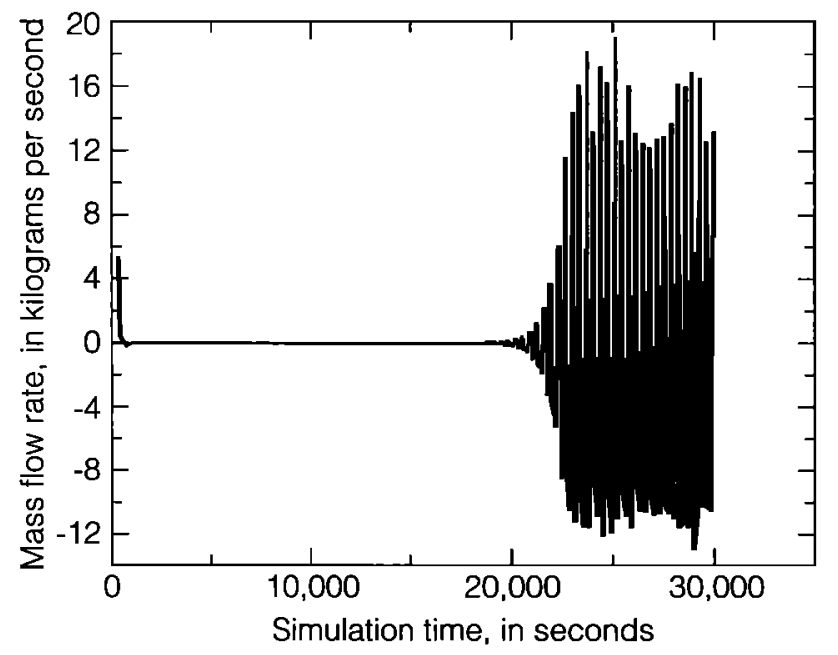

Figure 12. Effect of time step on "heat pipe" solution. The simulation began with a maximum time step of $240 \mathrm{~s}$, and within $2000 \mathrm{~s}$, a steady, liquid-dominated heat pipe solution was achieved (zero net mass flux). The heat pipe solution involved steady counterflow of $0.91 \mathrm{~kg} \mathrm{~s}^{-1}$, sufficient to balance the basal heat input of $2 \mathrm{MW}\left(0.91 \times\left(h_{\mathrm{s}}-h_{\mathrm{w}}\right)=2 \mathrm{MW}\right)$. At a simulation time of $10,000 \mathrm{~s}$, the maximum time step was reduced to $20 \mathrm{~s}$, and periodic oscillations began to develop. By about 23,000 s, a "steady" periodic solution was achieved, with a period of about $6 \mathrm{~min}$. Parameter values are as shown in Figure 2, except that the geyser conduit was assigned a permeability of $3 \times 10^{-8} \mathrm{~m}^{2}$.

ity of natural heat pipes tends to be much lower than the values used in our simulations, perhaps of the order of $10^{-15}$. $10^{-13} \mathrm{~m}^{2}$ [e.g., Lai et al., 1994], and the throughflow of energy tends to be much lower $\left(\sim 1 \mathrm{~W} \mathrm{~m}^{-2}\right.$, versus $2 \mathrm{MW} \mathrm{m}^{-2}$ in our simulations). The preference for the periodic solution seen in our results (Figure 12) might also be related to the much larger permeability and energy throughflow.

\section{Chaotic Behavior}

As is discussed in some detail in the following section, geyser periodicity may be affected by small (less than $1 \mu$ strain) strains induced by seismic events, barometric loading, and Earth tides. Unless such small perturbations cause significant changes in intrinsic or relative permeability, this responsiveness suggests that geyser periodicity can possess chaos. Analysis of a limited time series suggests that the periodicity of Yellowstone's Old Faithful does behave in a chaotic manner. Variations in its eruption frequency are not random; time series of periodicity have an autocorrelation structure that varies over time [Nicholl et al., 1994]. Thus it is worthwhile to examine to what extent our simulated geysers have a chaotic component.

We can identify the presence of chaos in many facets of our simulated geysers. As is expected for a chaotic system, the behavior of the geyser-discharge time series is strongly dependent on the degree of nonlinearity of the governing equations, as demonstrated by the strong influence of the relative permeability functions. Also, phase-space reconstructions of geyser discharge possess several strange attractors and are mildly sensitive to perturbations in initial conditions.
However, the geyser frequency itself is mostly predictable, with a small amount of chaotic noise.

Our simulations using the Corey relative permeability functions (Figure 8) are inherently more nonlinear than those that employ linear relative permeability functions. As a result of the increased nonlinearity, the behavior of the Corey geyser discharge time series is significantly more complex, as was seen in the difference between the power spectra of the time series (Figure 10).

We can also see the effect of added nonlinearity in phasespace reconstructions of the geyser discharge (Figure 13). These phase-space reconstructions are simply a three-dimensional plot of geyser discharge at a particular time $t$ versus geyser discharge one time increment previous $(t-\Delta t)$ versus geyser discharge two time increments previous $(t-2 \Delta t)$.
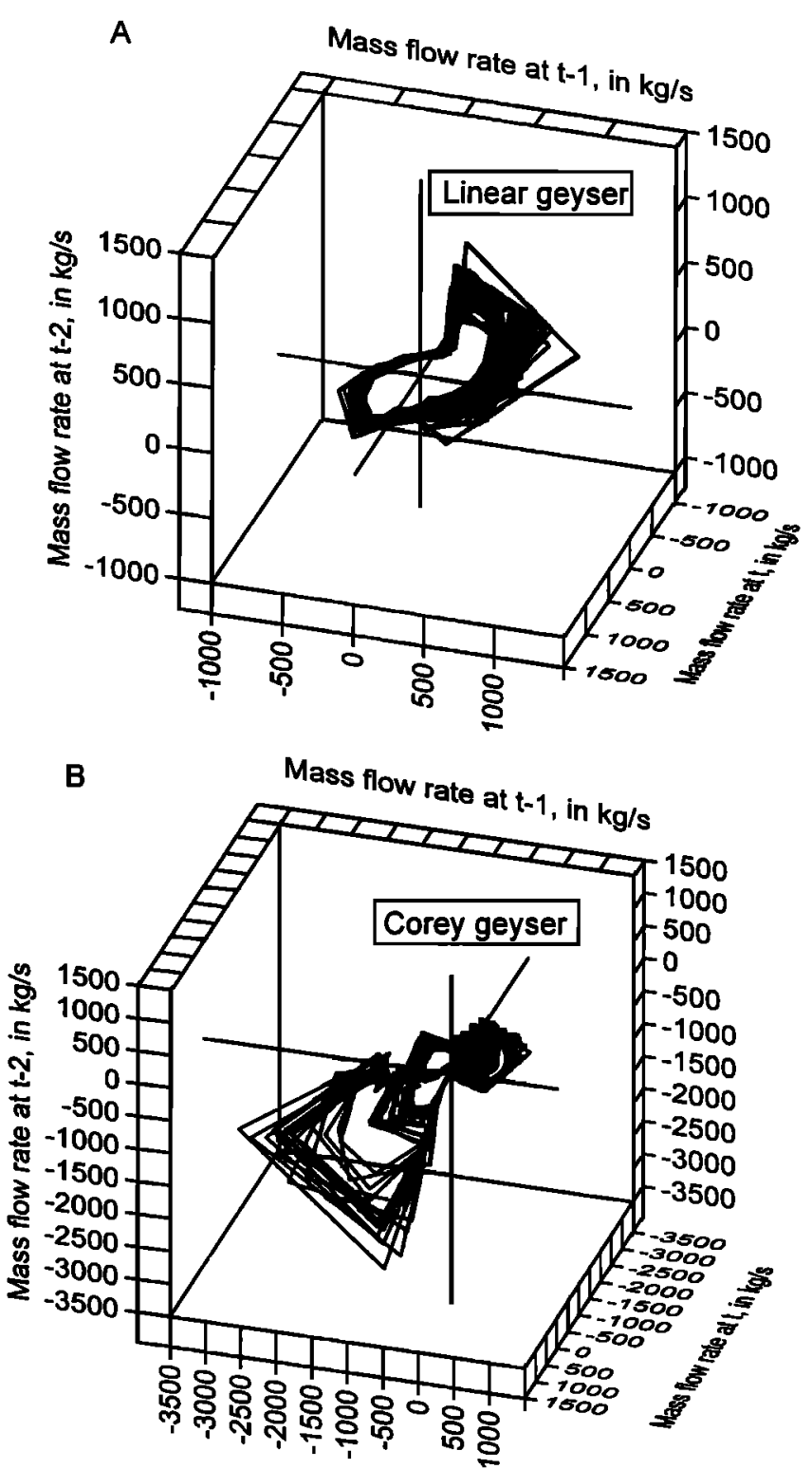

Figure 13. Phase-space reconstructions of (a) linear geyser and (b) Corey geyser. The phase-space reconstruction is a threedimensional plot of surface discharge at successive time increments. With the exception of Corey-type relative permeabilities for the Corey geyser, parameter values are as shown in Figure 2. 


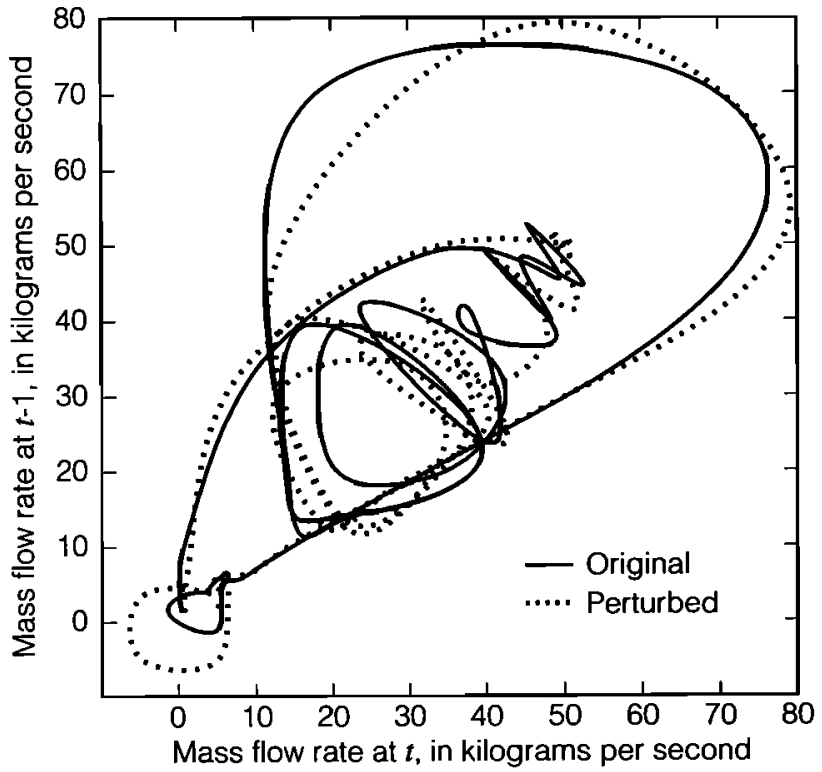

Figure 14. Effect of perturbation on phase-space reconstruction of Corey geyser. The perturbation consisted of reducing pressure in the topmost active node by $0.1 \%$ after $100,000 \mathrm{~s}$ of simulation time. The reconstructions (perturbed and unperturbed) are based on $3600 \mathrm{~s}$ of simulation time. With the exception of Corey-type relative permeabilities, parameter values are as shown in Figure 2.

Although the time steps used for these particular phase-space reconstructions are very coarse $(60 \mathrm{~s})$, the surface discharge for the Corey geyser clearly possesses many more attractors than the linear geyser. It should be noted that the "flow" or path of the phase-space reconstruction about the attractors does not repeat itself exactly, which is characteristic of chaotic systems.

As is required for the existence of chaos, the simulations also show some sensitivity to initial conditions. Phase-space reconstructions of geyser discharge are altered by perturbations in initial conditions. For example, Figure 14 shows a phase-space reconstruction based upon reducing pressure in the topmost active finite-difference block by $0.1 \%$ after $100,000 \mathrm{~s}$ of simulation time (about $90,000 \mathrm{~s}$ after the surface flux approached its periodic steady state). Viewed in comparison to the unperturbed simulation, the pressure change does alter surface discharge, and the trajectory of the flow does diverge from the original flow. However, the divergence is mild, and the flow possesses the same attractors as the undisturbed simulations. Comparison of the power spectra for the two time series (not shown) indicated negligible differences between the two time series. The frequency of geyser eruptions is essentially independent of the initial conditions.

Similarly, chaos is not identifiable in the phase-space reconstruction of the integrated surface discharge per geyser cycle (Figure 15); the mass discharge per eruption is essentially random about a mean. The process of integrating the surface discharge over the geyser cycle damps recognition of the temporal variability in our simulation.

In our simulations, then, chaos is present in the surfacedischarge time series but absent in time-integrated quantities such as geyser frequency and mass/energy release per eruption. Such integrated quantities are more important than the geyser-discharge time series because they can be quantitatively compared to real-world measurements. Although chaos in geyser periodicity may occur in the real world, there is little chaos in the simulated period.

If real-world geyser periodicity is chaotic, then the absence of such behavior in our simulations is simply another example of the limitations inherent in using models to simulate complex physical processes. Perhaps variability in real-world geysers is induced by the chaotic nature of external forces such as recharge. Alternatively, the stability of our model may indicate that we are still damping or ignoring significant physical processes. We have attempted to produce a more strongly chaotic system by refining time and space discretization and (or) changing the aspect ratio of the geyser conduit to enhance liquid-phase convection and found that these modifications had only a minor effect on time-integrated system behavior. However, there are still processes that we ignore that could produce a more chaotic system. Our Rey-

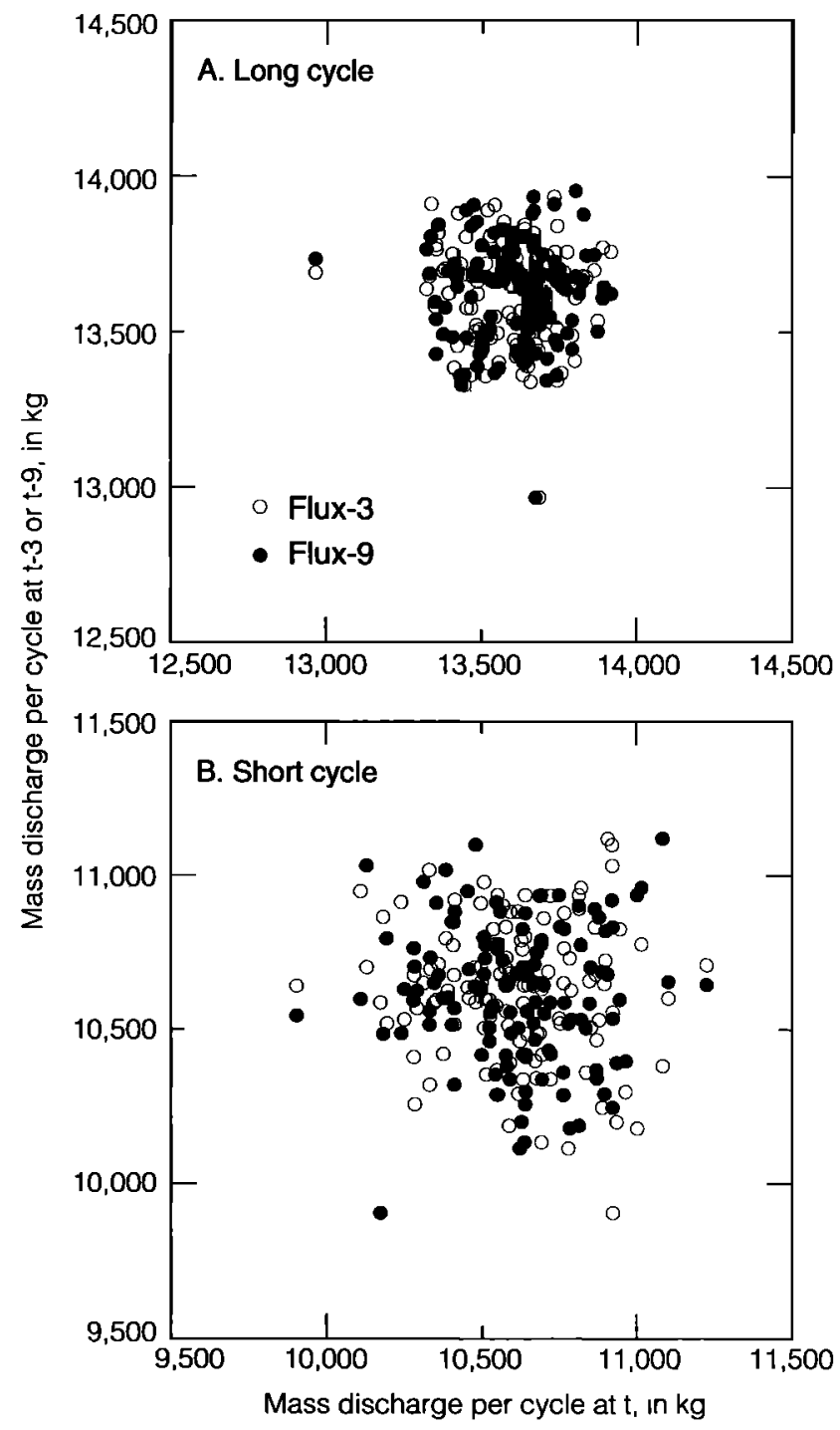

Figure 15. Phase-space reconstruction of discharge per geyser cycle for the (a) long and (b) short cycles of the Corey geyser. The reconstruction is based on mass flux three or nine cycles previous. With the exception of Corey-type relative permeabilities, parameter values are as shown in Figure 2. 
nolds number analysis suggests that turbulent drag may be important. However, turbulent drag seems likely to be a less significant source of nonlinearity than the various relative permeability functions. Other possibilities include heterogeneity in intrinsic and relative permeabilities and hysteresis in the relative permeability functions. We have seen that relative permeabilities strongly affect simulated geyser behavior. If the relative permeability functions are hysteretic and therefore dependent on the time history of the geyser cycle, it seems likely that a stronger chaotic signal will develop.

\section{Response to Small Strains}

As noted in the introduction, our interest in geysers was provoked by observations that geyser-eruption frequency is not constant in time and can vary in response to small strains in the Earth. Interaction with nearby geysers and hot springs appears to be another source of irregularity [Marler, 1951]. Even famously regular geysers such as Old Faithful, Yellowstone, exhibit bimodal [Rinehart, 1965] and (or) chaotic [Nicholl et al. , 1994] eruption patterns.

Some of the evidence for geyser response to small strains is summarized in Table 3 . There is compelling evidence for coseismic changes in eruption frequency. For example, the eruption frequency of the "Old Faithful" geyser in Calistoga, California, changed in conjunction with each of the last three M 6-7 earthquakes in central California [Silver and ValletteSilver, 1992]. These earthquakes were centered $\geq 130 \mathrm{~km}$ from Calistoga, and static strains at Calistoga were of the order of $0.1-1 \mu$ strain $\left(10^{-7}-10^{-6}\right)$ with dynamic strains about 1 order of magnitude greater [Hill et al., 1993]. Following the Oroville (1975) and Loma Prieta (1989) events, there was a marked decrease in eruption frequency, with a gradual recovery toward the preeruption frequency over a period of months. After the Morgan Hill (1984) event, there was a change from a unimodal to a bimodal eruption pattern. There is more subtle evidence for relatively small preseismic changes in the frequency of the Calistoga geyser, but any preseismic changes were well within its normal range of variation and therefore would not constitute useful precursory signals. Many of the geysers at Yellowstone responded to $M 7+$ earthquakes at Hebgen Lake (1959, distance $\sim 50 \mathrm{~km}$ ) and Borah Peak (1983, distance $\sim 230 \mathrm{~km}$ ) [Marler and White, 1977; Hutchinson, 1985]. After the Hebgen Lake event, the frequency of many semiregular geysers increased, long-dormant geysers erupted, and many hot springs erupted for the first time. Response to the more distant Borah Peak event was relatively slow, subtle, and variable.

Several geysers have been shown to be sensitive to periodic loading. White [1967] showed that the discharge of a geyser at Steamboat Springs, Nevada, responded to short-term variations in barometric pressure; discharge was inversely proportional to barometric pressure. Rinehart $[1972,1980]$ showed that the frequency of Old Faithful, Yellowstone, is proportional to the magnitude of the diurnal Earth tides. The strains caused by typical barometric pressure changes of about $2 \times 10^{3} \mathrm{~Pa}$ are of the order of $10^{-7}$, assuming negligible horizontal strain and a typical rock compressibility of $10^{-10}$ $\mathrm{Pa}^{-1}$, and the semi-diurnal and diumal tidal strains are about an order of magnitude smaller [Bredehoeft, 1967; Beaumont and Berger, 1975]. Assertions that the frequency of some geysers is affected by longer-period Earth tides or seasonal changes in barometric pressure [Rinehart, 1972] have been vigorously contested [White and Marler, 1972]. Most long. period Earth tides are associated with strain magnitudes of only a few nanostrains [Melchior, 1978].

Interestingly, thermally induced strains associated with heating and cooling during the geyser cycle may actually be larger than some of the externally imposed strains that have been shown to affect geyser function. In our simulations, cyclic temperature variations typically ranged from $\sim 1^{\circ} \mathrm{C}$ at $200 \mathrm{~m}$ depth to $5-10^{\circ} \mathrm{C}$ at $10 \mathrm{~m}$ depth. Birch and Kennedy [1972] measured cyclic variations of $\sim 20^{\circ} \mathrm{C}$ at $18 \mathrm{~m}$ depth in the conduit of Old Faithful, Yellowstone. Given typical rock expansivities of $10^{-5}{ }^{\circ} \mathrm{C}^{-1}$, such temperature variations translate to local strains of $\sim 10^{-4}$. Our simulations did not incorporate thermal expansion of the rock, and it would be difficult to do so realistically in the context of a model that

Table 3. Summary of Geyser Responses to Small Strains in the Earth

\begin{tabular}{|c|c|c|}
\hline Source of Strain & $\begin{array}{l}\text { Approximate } \\
\text { Strain } \\
\text { Magnitude }\end{array}$ & Nature of Geyser Response \\
\hline $\begin{array}{l}\text { Remote } \\
\text { earthquakes }\end{array}$ & $10^{-6}$ & $\begin{array}{l}\text { Increases in frequency and rate of discharge are common [e.g., Hutchinson, 1985]; there } \\
\text { are also well-documented instances of decreased frequency and changes in frequency } \\
\text { mode [Silver and Vallette-Silver, 1992]. }\end{array}$ \\
\hline $\begin{array}{r}\text { Barometric } \\
\text { changes }\end{array}$ & $10^{-7}$ & $\begin{array}{l}\text { There is fairly good evidence for decreasing discharge with increasing barometric pressure } \\
\text { from Steamboat Springs, Nevada [White, 1967]. Rinehart [1972] suggested that the gey- } \\
\text { ser at Calistoga, California, was influenced by seasonal changes in barometric pressure, } \\
\text { but White and Marler [1972] interpreted the Calistoga response as a recharge effect. }\end{array}$ \\
\hline $\begin{array}{l}\text { (Semi) } \\
\text { diurnal } \\
\text { tides }\end{array}$ & $10^{-8}$ & $\begin{array}{l}\text { The frequency of Old Faithful, Yellowstone, has been related to the magnitude of daily } \\
\text { changes in gravitational attraction [Rinehart, 1972]. }\end{array}$ \\
\hline $\begin{array}{l}\text { Long-period } \\
\text { tides }\end{array}$ & $10^{-9}$ & $\begin{array}{l}\text { Rinehart [1972] suggested that certain geysers respond to fortnightly or longer-period } \\
\text { tides. White and Marler [1972] questioned this assertion. }\end{array}$ \\
\hline $\begin{array}{l}\text { Preseismic } \\
\text { deformation }\end{array}$ & $10^{-9}-10^{-8}(?)$ & $\begin{array}{l}\text { Preseismic frequency changes at Calistoga, California, appear to be subdued versions of } \\
\text { the much larger coseismic responses. }\end{array}$ \\
\hline
\end{tabular}


does not explicitly calculate water-rock heat exchange. Like the actual heat exchange process and the relative permeabilities, the effects of thermal expansion would be highly dependent on the (unknown) solid-void geometries. It is possible that thermal expansion/contraction causes the permeability of parts of the geyser system to vary significantly over the course of a cycle [e.g., Germanovich and Lowell, 1992].

Our simulation results do provide a framework for considering the response of natural geysers to small, external strains. They suggest that eruption frequency should exhibit varying degrees of sensitivity to the permeability (Figures 7 and 9), porosity (Figure $5 \mathrm{a}$ ) and length (Figure $5 \mathrm{f}$ ) of the geyser conduit; the permeability of the surrounding rock matrix (Table 2) [see also Ingebritsen and Rojstaczer, 1993, Figure 5]; and recharge rates (Tables 1 and 2). We now must consider how these parameters might be affected by the various types of external strains.

Coseismic and postseismic changes in geyser frequency might be explained in terms of permeability changes caused by strong ground motion. At locations distant from the earthquake source, these dynamic strains are significantly larger than the static strains. Ground-motion-related permeability increases have been inferred from the response of water wells and streamflow to earthquakes tens of kilometers distant [e.g., Waller, 1966; Rojstaczer et al., 1995]. Increases in the permeability of the geyser conduit itself (Figures 7 and 9) or in the permeability of the surrounding rock matrix (Table 2) should increase eruption frequency, and increases in effective conduit length (Figure $5 \mathrm{f}$ ) should decrease eruption frequency. Because the dynamic shear strains caused by distant earthquakes are small [Hill, 1993], increases in effective conduit length might be related to reopening of a network of existing fractures, rather than creation of new fractures.

We invoke ground motion and associated fracture creation or reopening to alter permeability because, in an initially high-permeability environment, the changes in fracture aperture associated with seismically induced static strains of $\leq 10^{-}$ ${ }^{6}$ would not cause large changes in permeability. Significant elasticity-related changes in the permeability or porosity of the geyser conduit itself seem particularly unlikely. Because the permeability of the surrounding matrix might be $10^{3}-10^{4}$ times lower than that of the geyser conduit (Table 2), it could conceivably be affected by an elastic response. For instance, if the matrix has a fracture permeability given approximately by $k=N d^{3} / 12=10^{-11} \mathrm{~m}^{2}$, with $N=0.02 \mathrm{~m}^{-1}$ and $d=0.002$ $\mathrm{m}$, and a strain of $10^{-6}$ is wholly accommodated by this fracture set, then the matrix permeability would change by about $7 \%$. Such a change in intrinsic permeability would seem to be an upper bound, since we are assuming that the fractures are favorably oriented relative to the imposed deformation and have essentially an infinite compliance. The possibility remains that static strains could affect relative permeabilities much more significantly, by causing minor changes in saturation.

Here we are assuming, as seems reasonable, that there is little amplification of the static strain signal due to local inhomogeneities. For example, if a 100 -m-wide strip of land were shortened by $1 \mathrm{~cm}$ during seismic activity, we assume that the strain across the entire area would be a uniform $10^{-4}$. Clearly, heterogeneities in compliance such as those caused by the existence of fracture zones will cause the deformation to be somewhat non-uniform. However, because the length scale of the deformation is of the order of kilometers to tens of kilo- meters, local heterogeneities in compliance will cause relatively small spatial variations in strain.

Elastic responses to the strains of magnitude $10^{-8}-10^{-7}$ associated with periodic loading also seem unlikely to affect significant changes in intrinsic permeability. Earlier [Ingebritsen and Rojstaczer, 1993] we suggested that sensitivity to periodic loads might be explained in terms of differences in fluidpressure sensitivity to loading between a compliant geyser conduit and a less compliant matrix. For example, it seems reasonable to assume that a compliant geyser conduit has a high barometric efficiency [Jacob, 1940; Rojstaczer and Agnew, 1989]. As barometric pressure increases, then, fluidpressure increases in the geyser conduit associated with the increased surface load would be larger than those in the matrix, so that recharge rates and geyser activity would be reduced. This process could explain White's [1967] observations at Steamboat Springs. In contrast, loading associated with Earth tides would cause a more marked response in the matrix, owing to its lower compliance. Under peak tidal compression, compression of pore spaces would lead to a greater rise in fluid pressure in the matrix and thus to enhanced recharge.

The fluid-pressure changes caused by periodic loading are small, perhaps equivalent to $20 \mathrm{~cm}$ of hydraulic head for barometric effects and $1-2 \mathrm{~cm}$ of hydraulic head for the larger Earth tides. In our geyser simulations, comparable fluid-pressure changes have little effect on time-integrated system behaviors such as eruption frequency. The effects of small changes in the matrix-conduit head differential might be magnified if the geyser conduit had a significantly lower aspect ratio, as in the classic geyser chamber (Figure 1a). However, unless the geyser system possesses greater response to perturbations than our simulations, it would seem unlikely that perturbations in mass flux induced by periodic loading could have a large effect on geyser periodicity.

Our results thus far provide a reasonable context for explaining the coseismic response of geysers and perhaps also their response to the larger periodic loads. However, they seem unable to explain responsiveness to smaller strains, such as those related to Earth tides, small changes in atmospheric loading, and any possible preseismic deformation. Our simulated geyser systems could be more responsive if they were fully chaotic, that is, if slight differences in the coupled variables influenced subsequent time-integrated system behavior (e.g., eruption frequency). Alternatively, enhanced sensitivity might be caused by the phenomenon of "metastable" liquid water. It has been observed in both field (R.O. Fournier, U.S. Geological Survey, written communication, 1994) and laboratory contexts [Steinberg et al., 1982b] that liquid water in hot spring and geyser conduits can be superheated above its saturation temperature because some energy is required to nucleate a vapor phase. Under such metastable conditions, very minor pressure changes might retard or accelerate boiling and thus have a systematic effect on geyser frequency. In phase-space reconstructions of geyser-eruption frequency, this phenomenon would presumably be expressed as random noise rather than chaotic behavior.

\section{Summary}

In a one-dimensional system with a constant pressureenthalpy upper boundary and a constant heat flux lower boundary, periodic discharge can be caused by a heat flux sufficient to generate a mobile steam phase. The frequency and 
mass discharge per cycle are found to be roughly log linear functions of permeability. The discharge has geyser-like characteristics only for a narrow range of permeabilities. In a qualitative sense, the behavior of the system is not greatly influenced by assumptions of Darcian flow and perfect waterrock heat exchange. Results for various sets of relative permeability functions do exhibit qualitative differences including, in the case of Corey-type functions, a tendency toward bimodal discharge.

In systems with sources of mass recharge other than the upper boundary, steady two-phase discharge is a possibility, and the limits to periodicity are of interest. In a one-dimensional system and for a particular, narrow range of permeabilities, periodic discharge persists over a reasonably large range of lower boundary mass fluxes. In a two-dimensional system involving a high-permeability conduit embedded in a lower-permeability matrix, geyser-like behavior is dependent on the hydraulic characteristics of the matrix, as well as those of the conduit itself. If pressures in the matrix are nearhydrostatic, small $(\leq 500)$ conduit/matrix permeability contrasts lead to steady steam discharge, rather than periodic two-phase discharge. If pressures in the matrix are $125 \%$ of hydrostatic, small $(\leq 3000)$ conduit/matrix permeability contrasts lead to steady, liquid-dominated upflow.

Our simulation results provide a framework for considering the relative rarity of geysers and their likely life span. Geysering requires a narrowly defined set of physical conditions that are very rare in nature. Geyser geometry presumably evolves over time due to near-surface rock failure and geochemical reactions, and recharge can be expected to change significantly over short geologic time periods. Hence the special conditions that create geysers cannot be expected to be long-lived.

The simulations also provide a partial framework for understanding the responsiveness of natural geysers to small strains in the Earth. We suggest that changes in eruption frequency observed after remote earthquakes might be due to ground-motion-induced permeability changes. Barometric loading and tidal loading may affect geyser activity by influencing the fluid pressure differences between a relatively compressible and porous geyser conduit and a less compressible and less porous matrix. Because these signals are relatively small, such effects seem likely to be negligible unless the geyser periodicity is more responsive than in our simulations.

Acknowledgments. Earlier drafts of this paper benefited greatly from thoughtful reviews by our colleagues Robert Fournier and Larry Mastin, JGR referees Susan Kieffer, Robert McKibbin, and Ken Wohletz and JGR Associate Editor Robert Lowell. Support for S.A.R.'s portion of this research came from the National Science Foundation (NSF EAR 9405631 and EAR 9119082).

\section{References}

Bear, J., Hydraulics of Groundwater, 569 pp., McGraw-Hill, New York, 1979.

Beaumont, C., and J. Berger, An analysis of tidal strain observations from the United States of America, I, The laterally homogeneous tide, Bull. Seismol. Soc. Am., 65, 1613-1629, 1975.

Bercich, B.J., and R. McKibbin, Modelling the development of natural hydrothermal eruptions, Proc. N. Z. Geotherm. Workshop, 14th, 305-312, 1992. (Corrigendum: Proc. N. Z. Geothermal Workshop, 15th, 345-346, 1993.)

Birch, F., and G.C. Kennedy, Notes on geyser temperatures in Iceland and Yellowstone National Park, in Flow and Fracture of
Rocks, Geophys. Monogr. Ser. vol. 16, edited by H. C. Heard et al., pp. 329-336, AGU, Washington, D. C., 1972.

Bredehoeft, J.D., Response of well-aquifer systems to Earth tides, $J$. Geophys. Res., 72, 3075-3087, 1967.

Bryan, T.S., The Geysers of Yellowstone, 3rd ed., 463 pp., Univ. Press of Colo., Niwot, 1995.

Corey, A.T., Measurement of water and air permeabilities in unsaturated soil, Soil Sci. Soc. Am. Proc., 21, 7-10, 1957.

Dankworth, D.C., I.G. Kevrekidis, and S. Sundaresan, Dynamics of pulsing flow in trickle beds, AIChE J. 36, 605-621, 1990.

Dowden, J., P. Kapadia, G. Brown, and H. Rymer, Dynamics of a geyser eruption, J. Geophys. Res., 96, 18,059-18,071, 1991.

Faust, C.R., and J.W. Mercer, Geothermal reservoir simulation, 1, Mathematical models for liquid- and vapor-dominated hydrothermal systems, Water Resour. Res., 15, 23-30, 1979a.

Faust, C.R., and J.W. Mercer, Geothermal reservoir simulation, 2, Numerical solution techniques for liquid-and vapor-dominated hydrothermal systems, Water Resour. Res., 15, 31-46, 1979b.

Fournier, R.O., Old Faithful: A physical model, Science, 163, 304$305,1969$.

Fournier, R.O., Geochemistry and dynamics of the Yellowstone National Park hydrothermal system, Annu. Rev. Earth Planet. Sci., 17, 13-53, 1989.

Freeze, R.A., and J.A. Cherry, Groundwater, 604 pp., Prentice-Hall, Englewood Cliffs, N.J., 1979.

Germanovich, L.N., and R.P Lowell, Percolation theory, thermoelasticity, and discrete hydrothermal venting in the Earth's crust, Science, 255, 1564-1567, 1992.

Haar, L., J.S. Gallagher, and G.S. Kell, NBS/NRC Steam Tables, 320 pp., Hemisphere, New York, 1984.

Hayba, D.O., and S.E. Ingebritsen, The computer model HYDROTHERM, a three-dimensional finite-difference model to simulate ground-water flow and heat transport in the temperature range of 0 to $1,200^{\circ} \mathrm{C}$, U.S. Geol. Surv. Water Resour. Invest. Rep., 944045, 85 pp., 1994.

Hill, D.P., et al., Seismicity remotely triggered by the magnitude 7.3 Landers, California, earthquake, Science, 260, 1617-1623, 1993.

Hutchinson, R.A., Hydrothermal changes in the Upper Geyser Basin, Yellowstone National Park, after the 1983 Borah Peak earthquake, U.S. Geol.Surv. Open-File Rep., 85-290, pp. 612-624, 1985.

Ingebritsen, S.E., and S.A. Rojstaczer, Controls on geyser periodicity, Science, 262, 889-892, 1993.

Jacob, C.E., The flow of water in an elastic artesian aquifer, Eos Trans. $A G U, 21,574-586,1940$.

Kieffer, S.W., Seismicity at Old Faithful Geyser: An isolated source of geothermal noise and possible analogue of volcanic seismicity, J. Volcanol. Geotherm. Res., 22, 59-95, 1984.

Kieffer, S.W., Geologic nozzles, Rev. Geophys., 27, 3-38, 1989.

Kieffer, S.W., J.A. Westphal, and R.A. Hutchinson, A journey toward the center of the Earth: Video adventures in the Old Faithful conduit, Yellowstone Sci., 3(3), 2-5, 1995.

Lai, C.H., G.S. Bodvarsson, and A.H. Trusdell, Modeling studies of heat transfer and phase distribution in two-phase geothermal reservoirs, Geothermics, 23, 3-20, 1994.

Marler, G.D., Exchange of function as a cause of geyser irregularity, Am. J. Sci., 249, 329-342, 1951.

Marler, G.D, and D.E. White, Evolution of Seismic Geyser, Yellowstone National Park, Earthquake Inf. Bull., 9(2), 21-25, 1977.

McGuinness, M.J., M. Blakeley, K. Pruess, and M.J. O'Sullivan, Geothermal heat pipe stability: Solution selection by upstreaming and boundary conditions, Transp. Porous Media, 11, 71-100, 1993.

Melchior, P., The Tides of the Planet Earth, 607 pp., Pergamon, Tarrytown, N.Y., 1978.

Nicholl, M.J., S.W. Wheatcraft, and S.W. Taylor, Is Old Faithful a strange attractor?, J. Geophys. Res., 99, 4495-4503, 1994.

Ott, E., Chaos in Dynamical Systems, 385 pp., Cambridge Univ. Press, New York, 1993.

Rinehart, J.S., Earth tremors generated by Old Faithful Geyser, Science, $150,494-496,1965$.

Rinehart, J.S., Fluctuations in geyser activity caused by variations in Earth tidal forces, barometric pressure, and tectonic stresses, $J$. Geophys. Res., 77, 342-350, 1972.

Rinehart, J.S., Geysers and Geothermal Energy, 223 pp., SpringerVerlag, New York, 1980.

Rojstaczer, S., and D.C. Agnew, The influence of formation material properties on the response of water levels in wells to Earth tides 
and atmospheric loading, J. Geophys. Res., 94, 12,403-12,411, 1989.

Rojstaczer, S., S. Wolf, and R. Michel, Permeability enhancement in the shallow crust as a cause of earthquake-induced hydrological changes, Nature, 373, 237-239, 1995.

Sengers, J.V., and J.T.R. Watson, Improved international formulation for the viscosity and thermal conductibity of water substance, J. Phys. Chem. Ref. Data, 15, 1291-1314, 1986.

Silver, P.G., and N.J. Vallette-Silver, Detection of hydrothermal precursors to large northern California earthquakes, Science, 257, 1363-1368, 1992.

Snow, D.T., Rock fracture spacings, openings, and porosities, Proc. Am. Soc. Civ. Eng., 94, 73-91, 1968.

Sod, G., Numerical Methods in Fluid Dynamics, 433 pp., Cambridge Univ. Press, New York, 1985.

Sorey, M.L., M.A. Grant, and E. Bradford, Nonlinear effects in twophase flow to wells in geothermal reservoirs, Water Resour. Res., 16, 767-777, 1980.

Steinberg, G.S., A.G. Merzhavov, and A.S. Steinberg, Geyser process: Its theory, modeling, and field experiment, 2, A laboratory model of a geyser, Mod. Geol., 8, 71-74, 1982a.

Steinberg, G.S., A.G. Merzhavov, and A.S. Steinberg, Geyser process: Its theory, modeling, and field experiment, 3, On metastability of water in geysers, Mod. Geol., 8, 75-78, 1982b.

Tae-il, K., K. Okamoto, and H. Madarame, Study on the effective parameters for the geysering period, in Instabilities in Multiphase Flows, edited by G. Gouesbet and A. Berlemont, pp. 125-136, Plenum, New York, 1993.

Vennard, J.K., and R.L. Street, Elementary Fluid Mechanics, 5th ed., 740 pp., John Wiley, New York, 1975.

Waller, R.M., Effects of the March 1964 Alaska earthquake on the hydrology of south-central Alaska, U.S. Geol. Surv. Prof. Pap., 544-A, 28 pp., 1966.
Ward, J.C., Turbulent flow in porous media, Proc. Am. Soc. Civ. Eng., 90, 1-12, 1964.

White, D.E., Some principles of geyser activity, mainly from Steamboat Springs, Nevada, Am. J. Sci., 265, 644-684, 1967.

White, D.E., and G.D. Marler, Comments on paper by John S. Rinehart, 'Fluctuations in geyser activity caused by Earth tidal forces, barometric pressure, and tectonic stresses,' $J$. Geophys. Res., 77, 5825-5829, 1972.

White, D.E., L.J.P. Muffler, and A.H. Trusdell, Vapor-dominated hydrothermal systems compared with hot-water systems, Econ. Geol., 66, 75-97, 1971.

White, D.E., R.O. Fournier, L.J.P. Muffler, and A.H. Truesdell, Physical results of research drilling in thermal areas of Yellowstone National Park, Wyoming, U.S. Geol. Surv. Prof. Pap., 892, 70 pp., 1975.

$\mathrm{Xu}, \mathrm{W}$., and R.P. Lowell, Are two-phase hydrothermal systems stable? (abstract), Eos Trans. $A G U, 76(46)$, Fall Meet. Suppl., 599, 1995.

Young, R.M., Phase transitions in one-dimensional steady-state hydrothermal flows, J. Geophys. Res., 101, 18,011-18,022, 1996.

S. E. Ingebritsen, U.S. Geological Survey, 345 Middlefield Road, MS 439, Menlo Park, CA 94025. (e-mail: seingebr@usgs.gov)

S. A. Rojstaczer, Department of Geology and Center for Hydrologic Science, Duke University, Durham, NC 27708. (e-mail: stuart@geo.duke.edu)

(Received January 29, 1996; revised May 21, 1996; accepted July 18, 1996.) 